\title{
Structural condition assessment of reinforced-concrete bridges based on acoustic emission and strain measurements
}

\author{
Imane Bayane ${ }^{1}$ (i) $\cdot$ Eugen Brühwiler ${ }^{1}$
}

Received: 8 June 2020 / Revised: 17 August 2020 / Accepted: 21 August 2020 / Published online: 5 September 2020

(c) The Author(s) 2020

\begin{abstract}
A reliable novel monitoring approach is developed to assess the structural condition of reinforced-concrete bridge elements. The approach is based on combining acoustic emission technique and strain gauge measurements, and it is illustrated by a case study of a composite steel-concrete viaduct in service since 1957. Monitoring was performed on its reinforced-concrete deck slab under traffic and environmental loading for one year. The monitoring setup and procedure are presented. The variation of acoustic emission signals is evaluated regarding strain and temperature measurements. Parametric study, pencil-break test, statistical analysis, crack classification and $b$-value analysis are performed to assess the structural condition. The acoustic emission activity of the reinforced-concrete slab is evaluated for 1 year under operational conditions. From the monitoring approach, it was possible to identify the nature of the cracking activity in the concrete slab as a function of traffic loading and temperature and to assess in time the condition of the slab-girder connection.
\end{abstract}

Keywords Monitoring $\cdot$ Road bridge $\cdot$ Acoustic emission (AE) $\cdot$ Strain measurement $\cdot$ Structural condition $\cdot$ AE feature . Parametric study $\cdot b$-value analysis $\cdot$ Cracking mode

\section{Introduction}

The sustainable and economical use of existing reinforcedconcrete (RC) bridges requires reliable assessment of their current condition under service loading. For road bridges, $\mathrm{RC}$ deck slabs are the most fatigue vulnerable part due to the pronounced effect of vehicle's axles [1-5]. RC decks often need assessment to meet both the safety and serviceability requirements of infrastructures particularly with the increase of the magnitude and frequency of axle loads.

The assessment of RC decks refers to the early stage assessment of concrete and steel reinforcement condition, as well as the bond between them. The effect of cyclic loading on RC structural elements was investigated in [1, 6-10]. However, most of these studies were limited to laboratory testing and only few have performed assessment on real structures. Different NDT methods were used to evaluate bridges on site such as radar, impact echo, and infrared

Imane Bayane

imane.bayane@epfl.ch

1 Laboratory of Maintenance and Safety of Structures (MCS), Swiss Federal Institute of Technology (EPFL), Lausanne, Switzerland thermography [11-13]. Such methods allow to detect delamination, moisture, and discontinuities in concrete but are limited for initial microcrack detection.

Early stage assessment is often restricted to visual inspections [14-16] that are subjective and not always reliable, or calculations of structural capacity [17], which are very conservative with the unrealistic assumptions and models related to loading and material properties. The assessment of $\mathrm{RC}$ decks requires methods that can give both the structural characteristics and response of RC structural elements under traffic and environmental loading.

The acoustic emission (AE) method has been proven to be efficient to assess the condition of concrete and steel. Being drawn from the physical phenomena of elastic wave propagation, it was widely used to investigate internal changes in materials under loading and to detect and classify crack initiation and propagation at an early stage [18-21].

The term "acoustic emission" refers to transient elastic stress waves generated by the energy released when microstructural changes occur in a material [22]. AE technique is based on recording the surface vibration of these waves. Stress waves propagate from the AE source toward the sensors, and during the propagation, they are influenced by a variety of factors such as propagation velocities, 
attenuations, discontinuities, and the geometry of the material. Recording stress waves can provide, therefore, information about the mechanical and geometrical properties of the environment in which they propagate. More details about the basis of this technique can be found in [23-25].

AE verification of RC structural elements under cyclic loading has been studied by many researchers [26-31]. However, most of them were limited to laboratory testing. Pronounced noise, complex loading, environmental conditions, as well as calibration and lack of reference present challenges for translating AE laboratory knowledge to the field.

Few research studies [23, 32-36] have demonstrated the feasibility of AE assessment of RC road bridges, but often for occasional testing under a load test. In fact, the interpretation of the AE measurements is difficult when the loading condition is unknown. Moreover, the huge amount of generated AE data under traffic presents a storage challenge. To the best of the authors' knowledge, there has been no work performing AE continuous long-term monitoring on $\mathrm{RC}$ decks in service and relating the $\mathrm{AE}$ response to traffic and environmental changes.

\section{Research significance and originality}

Fatigue of reinforced concrete belongs to the most studied research topics and AE technique has been widely used for fatigue crack detection and classification [8, 21, 26, 29, 37]. Nevertheless, many essential questions have not been answered so far. For instance, no sufficient explanation has been given about the mechanisms of degradation of RC structural elements under traffic and environmental loading. Another important point that lacks explanation is applying $\mathrm{AE}$ technique to investigate at an early stage the evolution of RC cracking activity on site.

To address these challenges, the last advances of the $\mathrm{AE}$ technique were used to perform a long-term monitoring campaign on an $\mathrm{RC}$ road bridge. The study is focused on initial cracking of concrete due to fatigue under traffic and environmental loading. It is illustrated with a case study in which no other mechanism of degradation has occurred based on engineering expertise. The AE technique was associated with strain gauges and thermocouples to connect $\mathrm{AE}$ measurements with vehicle loading and environmental changes. The approach provides both the structural response, i.e., reinforcement strain and temperature of concrete, and structural characteristics i.e. material properties and the condition of structural element connections and supports (Fig. 1).

The originality of this work includes:

- development, calibration, and synchronization of the monitoring approach;

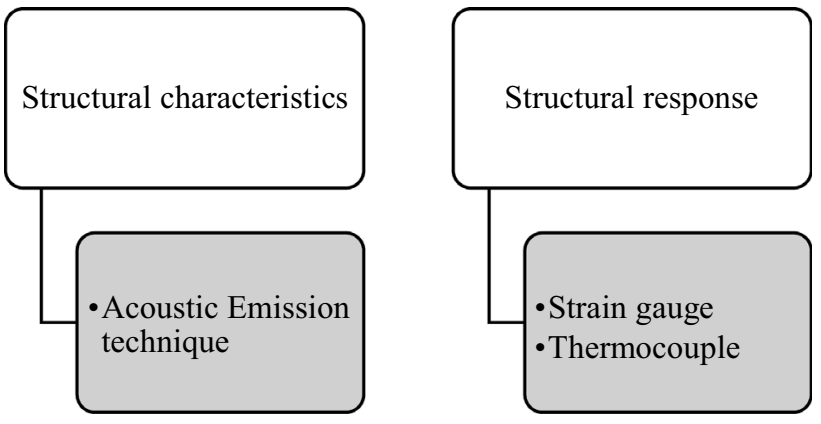

Fig. 1 Diagram of the monitoring approach

- identification of the annual variation of AE features with temperature;

- identification of the annual variation of AE features with traffic loading;

- investigation of initial stage of cracking phenomena in concrete with respect to traffic and thermal changes;

- assessment of structural characteristics and structural response of an RC deck slab based on acoustic and strain measurements.

\section{Monitoring of an RC road bridge}

\subsection{Structural description}

The presented case study relates to a composite steel-concrete viaduct, in service since 1957. It has two road lanes with a width of $10.5 \mathrm{~m}$. The viaduct comprises seven articulated spans of $25.6 \mathrm{~m}$ length and an approach span of $15.8 \mathrm{~m}$. Each span is made from two steel girder beams with a height of $1.3 \mathrm{~m}$, fixed in an RC slab of thickness varying from $0.17 \mathrm{~m}$ in the mid-span to $0.24 \mathrm{~m}$ (Fig. 2). The slab comprises longitudinal and transverse reinforcement rebars in both the tensile and compression zones with diameters of $10 \mathrm{~mm}, 14 \mathrm{~mm}$, and $18 \mathrm{~mm}$.

\subsection{Monitoring system}

The monitoring system comprises strain gauges, thermocouples, acoustic emission (AE), and ultrasonic testing (UT) system. It is illustrated in Fig. 3. Spans 2 and 4 were instrumented in July 2016 with strain gauges and thermocouples. Span 4 was additionally instrumented in December 2018, using the UT and AE systems. In total, 3 years of strain and temperature measurements, few months of pulsing signals, and one year of AE data were recorded and processed.

The data acquisition unit of strain is a Quantum MX1615, acquiring strain with a high frequency varying between 50 and $100 \mathrm{~Hz}$, from 8 strain gauges with half-bridge configuration and 2 strain gauges with 
Fig. 2 Case study, Crêt de l'Anneau viaduct, units in (m)

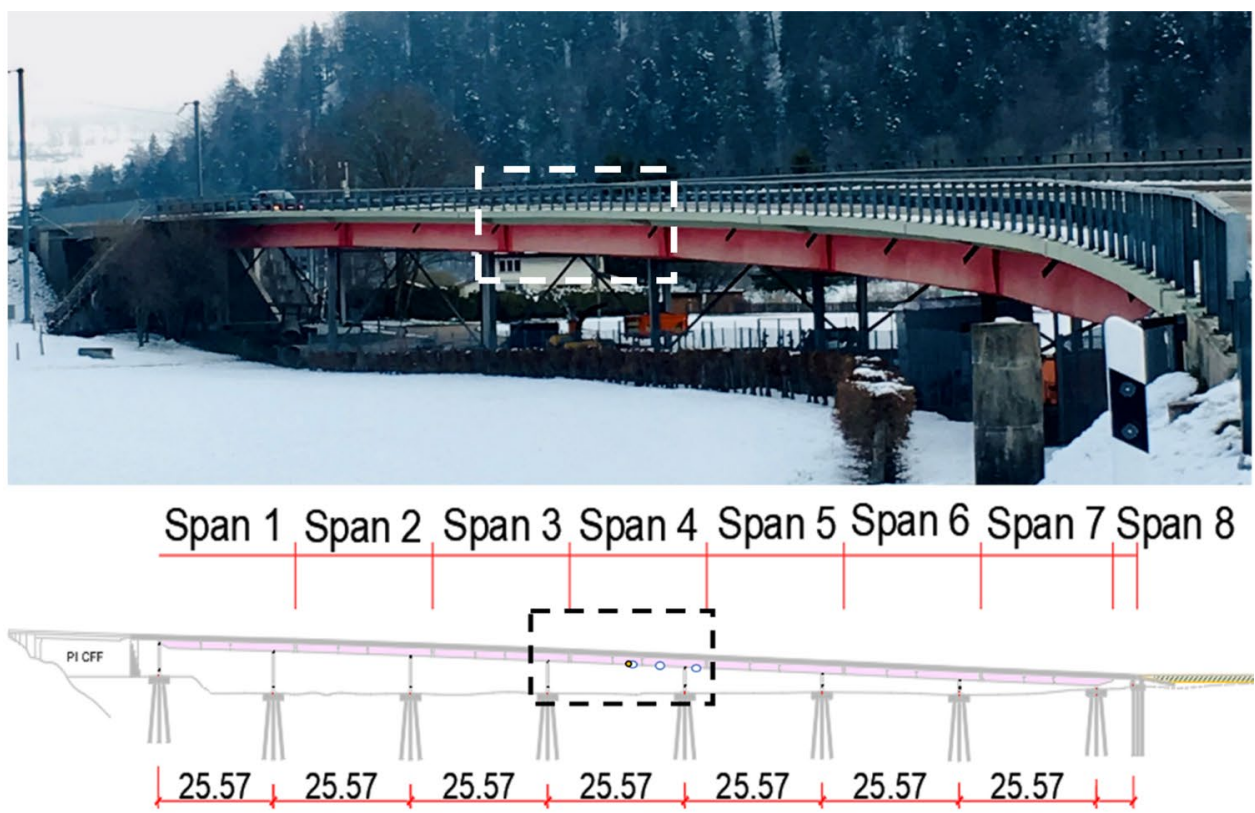

15.8

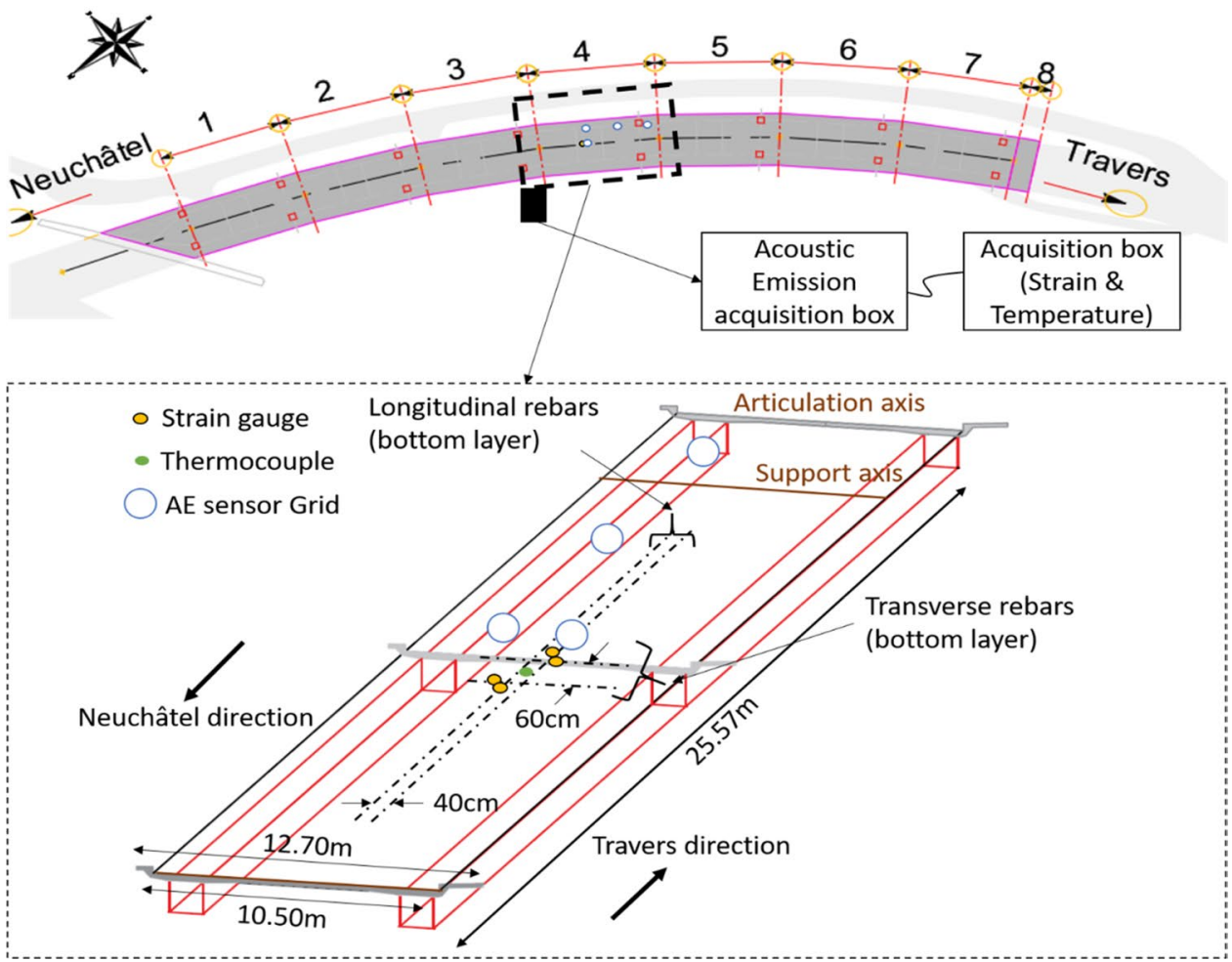

quarter-bridge configuration. The data acquisition unit of temperature is a Quantum MX1609, measuring temperature with a high frequency of $1 \mathrm{~Hz}$, from six thermocouples. An output and input unit comprised of Quantum MX879B was used to acquire recorded data, connect the system with a $4 \mathrm{G}$ internet connection, and connect strain and temperature measurement units with the AE acquisition system.
The data acquisition unit of strain was equipped with a monitor to visualize the measurements on-site. Catman program (a data acquisition software) was used to integrate all the units together and to visualize and parametrize data analysis.

The data acquisition system of AE technique is a sensor Highway for in-situ monitoring, comprised of a Processor Atom N2600, with a memory card of 128 Go and 


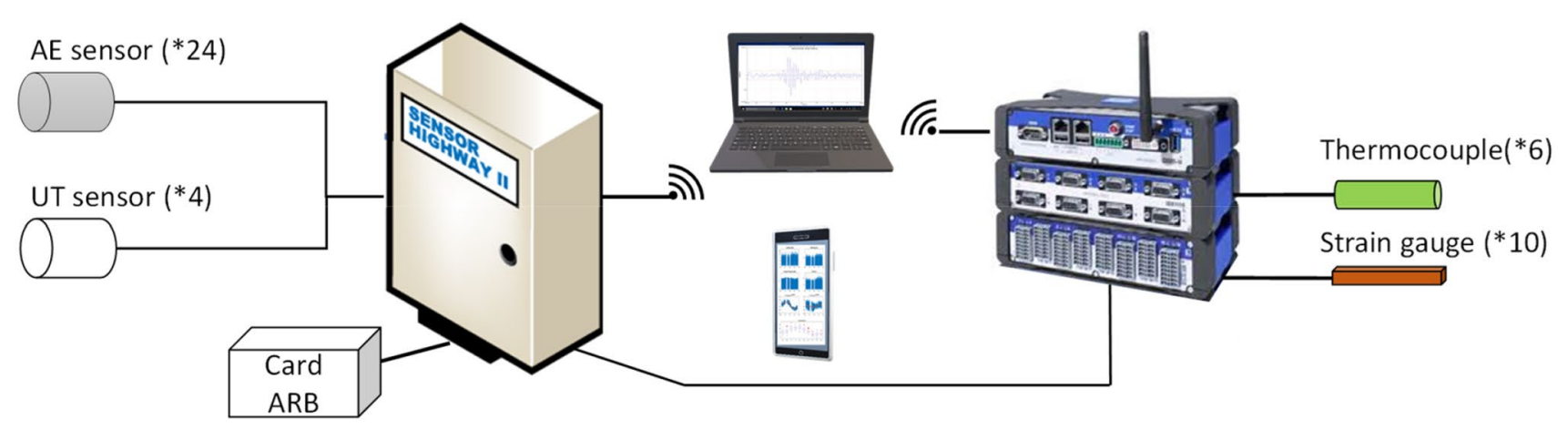

Fig. 3 Configuration of the monitoring system

32 acquisition channels of bandwidth range from 1 to $400 \mathrm{kHz}$, at $-3 \mathrm{~dB}$. The system was acquiring data from 24 resonant sensors PK151, resonating at $150 \mathrm{kHz}$ with an integrated preamplifier of $26 \mathrm{~dB}$ gain. The sensors detect transient waves and convert them to an electrical signal. Resonant sensors were used because of their high sensitivity and since the emission is strongly attenuated in concrete. The integrated preamplifiers were used to avoid signal loss. AE is insensitive to structural resonance since it only detects high-frequency events.

The same AE acquisition system was used to record the response of the generated waves by the UT system. This was made technically possible by the use of a card ARB-1410-150 generating arbitrary waveforms, a multiplexer with four channels on the card ARB, 4 sensors PK 151 resonating at 75 and $150 \mathrm{kHz}$, and an industrial calculator connected to the ARB card and controlled by the $\mathrm{AE}$ data acquisition system. The frequency of interaction between the sensors and the card was fixed at $800 \mathrm{kHz}$ to get the last arrivals of the waves while the frequency of pulses was $150 \mathrm{kHz}$ to be suitable for concrete (with the maximum aggregate diameter of $32 \mathrm{~mm}$ ). The results of the UT system are not further discussed in this paper.

The acquisition system was equipped with a monitor to visualize the data on-site and a $4 \mathrm{G}$ connection internet for remote access using a remote connection program. AEwin program (a commercial software for real-time "simultaneous" AE feature and waveform processing) was used to visualize in real time the generated waves and the $\mathrm{AE}$ features.

Data were recorded, stored, and collected every $24 \mathrm{~h}$, using the file transfer protocol (FTP). AE data were stored as DTA file, with $400 \mathrm{~GB}$ of collected data during the period of monitoring from 14/03/2019 to 14/03/2020. Strain data were stored as Matlab file, with 39 GB of data collected during the last year of monitoring.

\subsection{Instrumentation}

Sensors were installed in the accessible critical parts that provide easy interpretation of the recoded data to understand the structural behavior. Therefore, strain gauges were installed at the mid-span, and AE sensors were mounted in the mid-span and in three different longitudinal zones in the lane with the highest number of heavy trucks (Fig. 2). All the sensors were mounted on the underside of the RC slab since there is no access from the top side.

Spans 2 and 4 were instrumented each with four strain gauges with half-bridge configuration. Two were installed in the adjacent longitudinal rebars at mid-span and the two others were installed in the two-perpendicular transverse rebars (Fig. 2). The rebars were detected with a rebar locator (profometer), and an area of $50 \times 50 \mathrm{~mm}$ of the concrete cover was removed to uncover the rebars. Strain gauges were glued on each rebar and sealed with a protective layer to avoid any contact with air.

The top and bottom flanges of one steel box girder of Span 4 were instrumented each with a strain gauge with quarter bridge configuration. The painting was removed, and the surface was cleaned, and then the strain gauge was glued and covered with the protection layer.

Thermocouples were installed in the concrete near strain gauges at the mid-span of Spans 2 and 4, and at the top and bottom flanges of the steel girder of Span 4 .

To monitor the smooth functioning of the setup, one thermocouple and one humidity sensor were installed in the box of strain and temperature acquisition units.

The AE sensors (1-24) were mounted on four grids as it is illustrated in Fig. 4. The first grid is a circular network of six sensors (Channels 5, 6, 7, 17, 21, 22) with a diameter of $0.34 \mathrm{~m}$ installed at the mid-span. The second grid is comprised of nine sensors (Channels 8, 9, 10,11, 12, 18, 19, 20,24) spaced in a grid of $0.24 \mathrm{~m}$ and installed at the mid-lane, $1.35 \mathrm{~m}$ away 


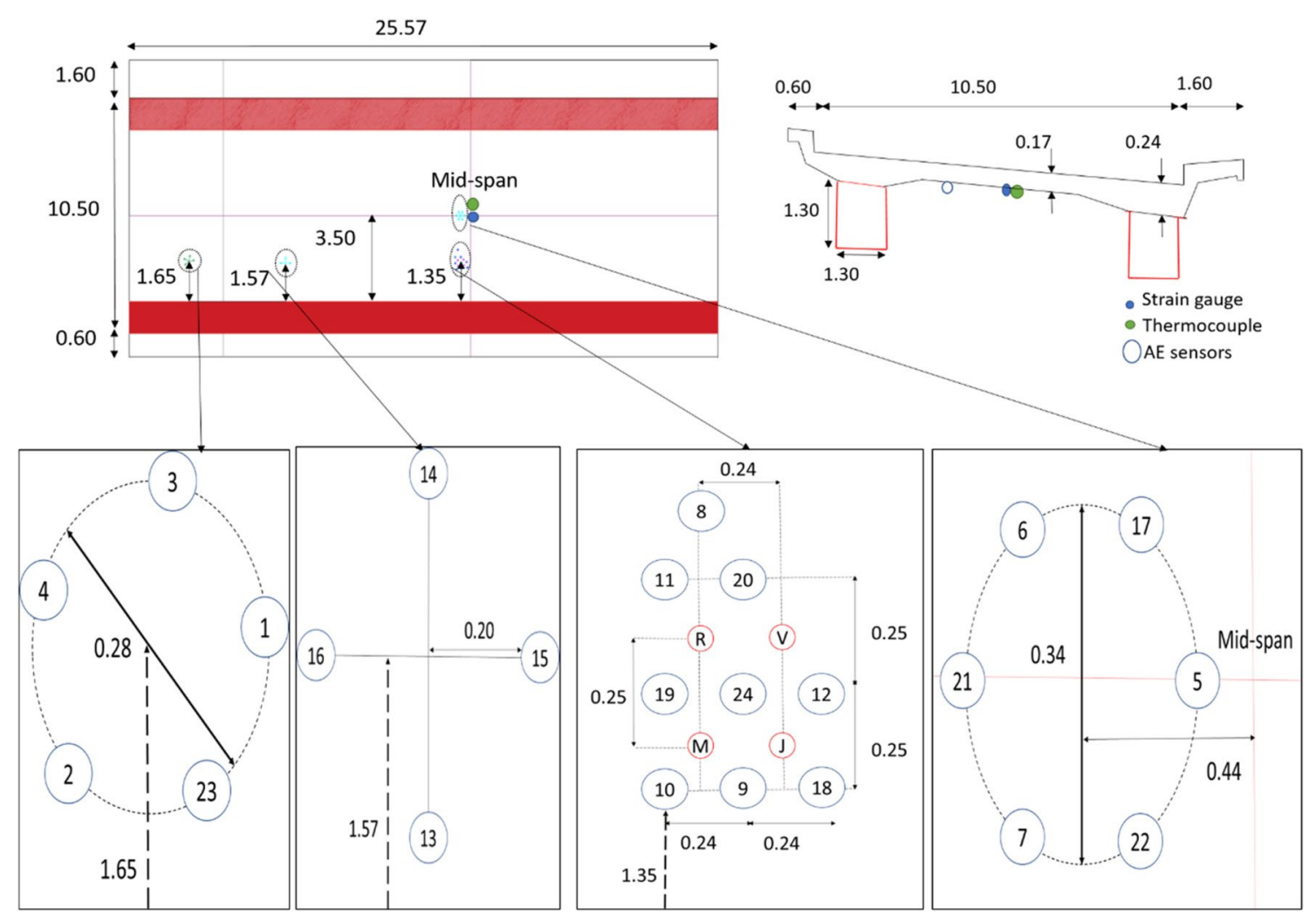

Fig. 4 Plan view showing the instrumented Span 4 and the deployment of AE sensors, dimensions in (m)

from the girder. The third grid is comprised of four sensors (Channels 13, 14, 15, 16) spaced in a grid of $0.20 \mathrm{~m}$, installed near the support, $1.57 \mathrm{~m}$ away from the girder. The fourth grid is a circular network of five sensors (Channels 1, 2, 3, 4, 23) with a diameter of $0.28 \mathrm{~m}$ installed between the support and the articulation. The UT sensors (M, R, V, J) were distributed among the network of nine AE sensors between the mid-span and the girder (Fig. 4).

The sensors were mounted using silicone glue to provide a direct and flexible connection between the contact surfaces of concrete and the sensors and were fixed with magnetic holders attached by metal plates screwed in concrete to ensure strong fixation. The surface of the concrete was smoothened and cleaned before the mounting, and the rebars were detected using a profometer to avoid installing the sensors directly underneath the rebars. The electronic noise coming from the interaction between the cables of connection of the AE system and UT system was mitigated by fixing the cables far away from each other.

\subsection{Calibration}

\subsubsection{Strain gauges}

A load test was carried out after instrumenting Spans 2 and 4 with strain gauges. A five-axle truck with a maximum load of $400 \mathrm{kN}$ was used to perform four passages per direction with four speeds. Transverse rebars were under tensile stresses during the passage of the truck. In the longitudinal direction, the girder and the rebars showed the expected stress reversal, i.e., both tensile and compressive stresses, due to vehicle passage.

The measured strains were mainly influenced by truck position and by slab slenderness that accentuates local strains under the wheels. The axle configuration of the loadtest truck does not have any influence on the response of the transverse reinforcement and the steel girder, which means that, during the monitoring campaign, the effect of vehicles can be directly related to their total load [38]. 


\subsubsection{Acoustic emission}

The evolution of AE activity under traffic and environmental conditions was preliminarily measured continuously over two months after instrumenting Span 4 with AE sensors. The recorded signals were analyzed to define the filters for suitable noise precautions for long-term monitoring.

Real-time visualization of $\mathrm{AE}$ activity was possible for a threshold above $30 \mathrm{~dB}$. To delete totally the noise of traffic, the waveforms with counts between, 5 and 10,000, and amplitudes between 40 and $1000 \mathrm{~dB}$ were recorded. A time filter was defined for peak definition time (PDT), hit definition time (HDT) and hit lockout time (HLT) as shown in Table 1 with channel setups and filters. Under the chosen filters, no AE activity was observed in the absence of traffic.

Sensor calibration and signal attenuation were performed with the pencil break method according to the standard NF EN 1330-9, 2017 [39], during the installation and 2 months after. Five pencil breaks were completed $0.05 \mathrm{~m}$ away from each sensor. The three highest recorded amplitudes must be higher or equal than $80 \mathrm{~dB}$ [40], and the measured value must have a variation of less than $\pm 3 \mathrm{~dB}$ from the mean amplitude value of all the sensors. Pencil break tests were conducted for each sensor and the recorded amplitudes were evaluated. When the sensors were not giving a response according to the requirements, the coupling and fixation were repeated.

\section{Data processing methods}

In this paper, the recorded AE signals during 1 year of continuous monitoring (from 14/03/2019 to 14/03/2020) were evaluated based on parametric analysis, pencil lead break testing, $b$-value analysis, and crack identification methods.

Three parameter inputs were used to connect strain measurement system with the AE data acquisition system: longitudinal strain at mid span, transverse strain at mid span, and concrete temperature at mid span. This provides the same time base and thus the synchronization for strain-temperature measurements and $\mathrm{AE}$ recorded signals.

An inverse analysis was conducted on strain measurements, using load-test data to calculate the position and load distributions of the vehicles crossing the viaduct. Action effects of traffic were identified along with the resulting AE signals, which provides a robust comparison and analysis basis with the high amount of synchronized data.

\subsection{Parametric analysis}

AE features were extracted from the recorded waves using AEwin program. The extracted features were analyzed and classified using single link clustering (Fig. 5). For each detected hit, AE features were extracted with the corresponding values of the input parameters of strain (parametric 1), and temperature (parametric 2). They are defined as follows [41]:

Channel is a single AE sensor and the related equipment components for transmitting conditioning, detecting and measuring the signals that come from it.

Rise time is the time from first threshold crossing the highest voltage point in the waveform ( $\mu \mathrm{s})$.

Counts to peak (Pcount) is the number of threshold crossings from first to highest voltage point on the waveform. Counts is the number of times the signal crosses the detection threshold.

Energy is the time integral of the absolute energy signal voltage.

Duration is the time from first to last threshold crossing $(\mu \mathrm{s})$.

Amplitude is the highest voltage in the $\mathrm{AE}$ waveform expressed on decibel (dB).

Average frequency (AF) is equal to counts divided by duration $(\mathrm{kHz})$.

Table 1 AE setup

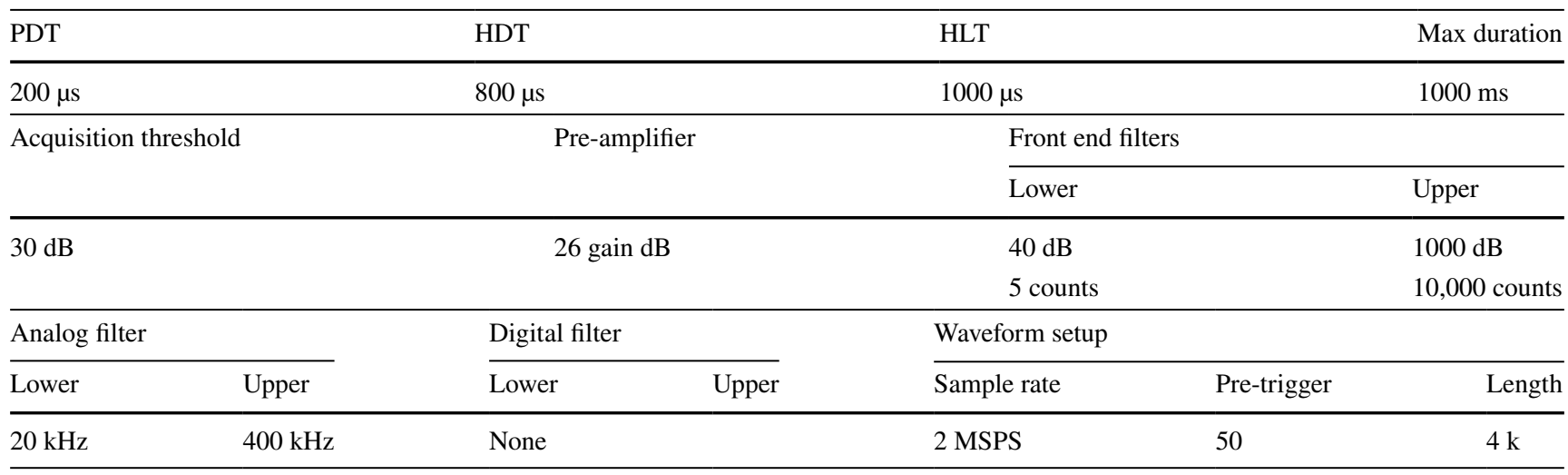




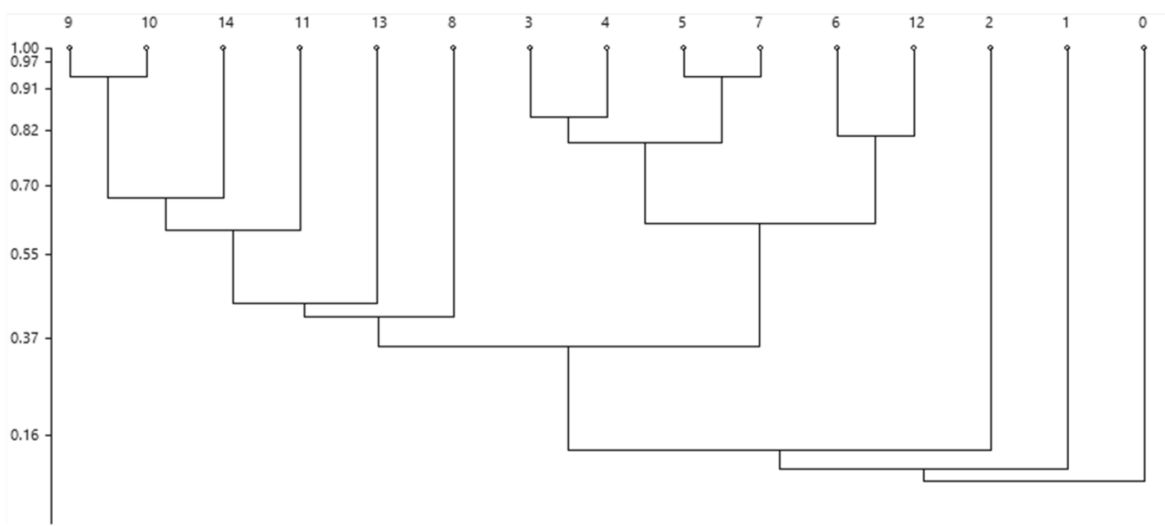

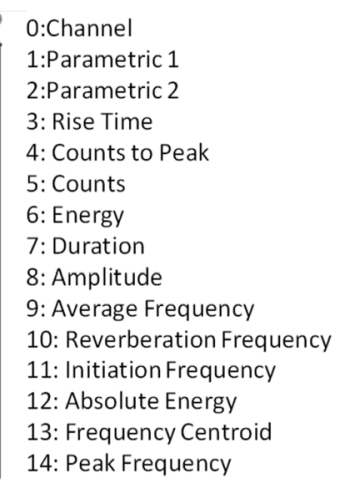

0:Channel

4: Counts to Peak

: Counts

9: Average Frequency

10: Reverberation Frequency

13: Frequency Centroid

14: Peak Frequency

Fig. 5 Single link clustering of AE features

Reverberation Frequency is equal to (counts-counts to peak) divided by (duration-rise time) $(\mathrm{kHz})$.

Initiation frequency is equal to counts to peak divided by rise time $(\mathrm{kHz})$

Absolute energy (ABSenergy) is the time integral of the square of the signal voltage at the sensor before any amplification divided by $10 \mathrm{k} \Omega$ impedance and expressed in attojoules (aJ).

Frequency centroid is the center of mass of the power spectrum graph $(\mathrm{kHz})$.

Peak frequency is the point where the power spectrum if greatest $(\mathrm{kHz})$.

Event is a local material change giving rise to AE.

Hit is the process of detecting and measuring an AE signal on a channel.

From Fig. 5, it can be observed that average frequency (AF) and reverberation frequency were highly correlated. Therefore, the AF was selected to perform the analysis while the peak frequency, initiation frequency, and frequency centroid will be investigated in future work. Similarly, counts to peak, duration, and absolute energy were selected for data processing, because of the high correlation of rise timecounts to peak, counts-duration and energy-absolute energy.

Parametric analysis was performed using the selected $\mathrm{AE}$ features along with the amplitude of the signals and the input parameters, i.e. strain and temperature. The recorded waves during 1 year of monitoring were extracted and analyzed using AEwin program and Matlab. The annual variation of the selected AE features was calculated for the 24 channels.

\subsection{Pencil break}

Pencil lead break testing is a preferred method for calibrating and evaluating the precision of the $\mathrm{AE}$ instrumentation since it presents an accurate mechanical source to identify propagation velocity characteristics and source location accuracy [42]. Pencil lead is pressed against the target surface until lead breaks generating a release of accumulated stress in the form of elastic waves. Lead break localization and wave velocity calculation can be performed to evaluate the tested material. Pencil lead break testing was used to investigate the AE activity during traffic loading and to measure the velocity of stress waves. In general, concrete with a P-wave velocity of more than 3500 or $4500 \mathrm{~m} / \mathrm{s}$ is evaluated to be good or excellent, while concrete with a velocity less than 3000 or $2000 \mathrm{~m} / \mathrm{s}$ is considered as poor or very poor [43].

\subsection{Cracking process}

Cracking of concrete is different from metals; it is preceded by microcracking instead of yielding. It is, therefore, characterized by a fracture zone and not a crack tip, where the stresses are decreasing when deformation is increasing [44]. Figure 6 shows how AE features vary during concrete cracking. The friction at the level of fracture zone and between existing cracks creates slow transverse/shear waves (Fig. 6b), while the creation of a new crack with two separated surfaces and the opening and closing of existing cracks generate a variation in the volume, resulting in fast longitudinal/ compression waves (Fig. 6a).

Concrete under high-cycle fatigue loading goes through crack nucleation, crack propagation and finally apparition of long cracks until failure [45]. The concrete of the 60-year slab is estimated to be in the stage of crack propagation.

\subsection{Cracking modes}

Wave modes are exited differently with different cracking types. Tensile cracks cause a transient volumetric change inside the material, converting the released energy mainly into P-waves. The resultant AE events are longitudinal 


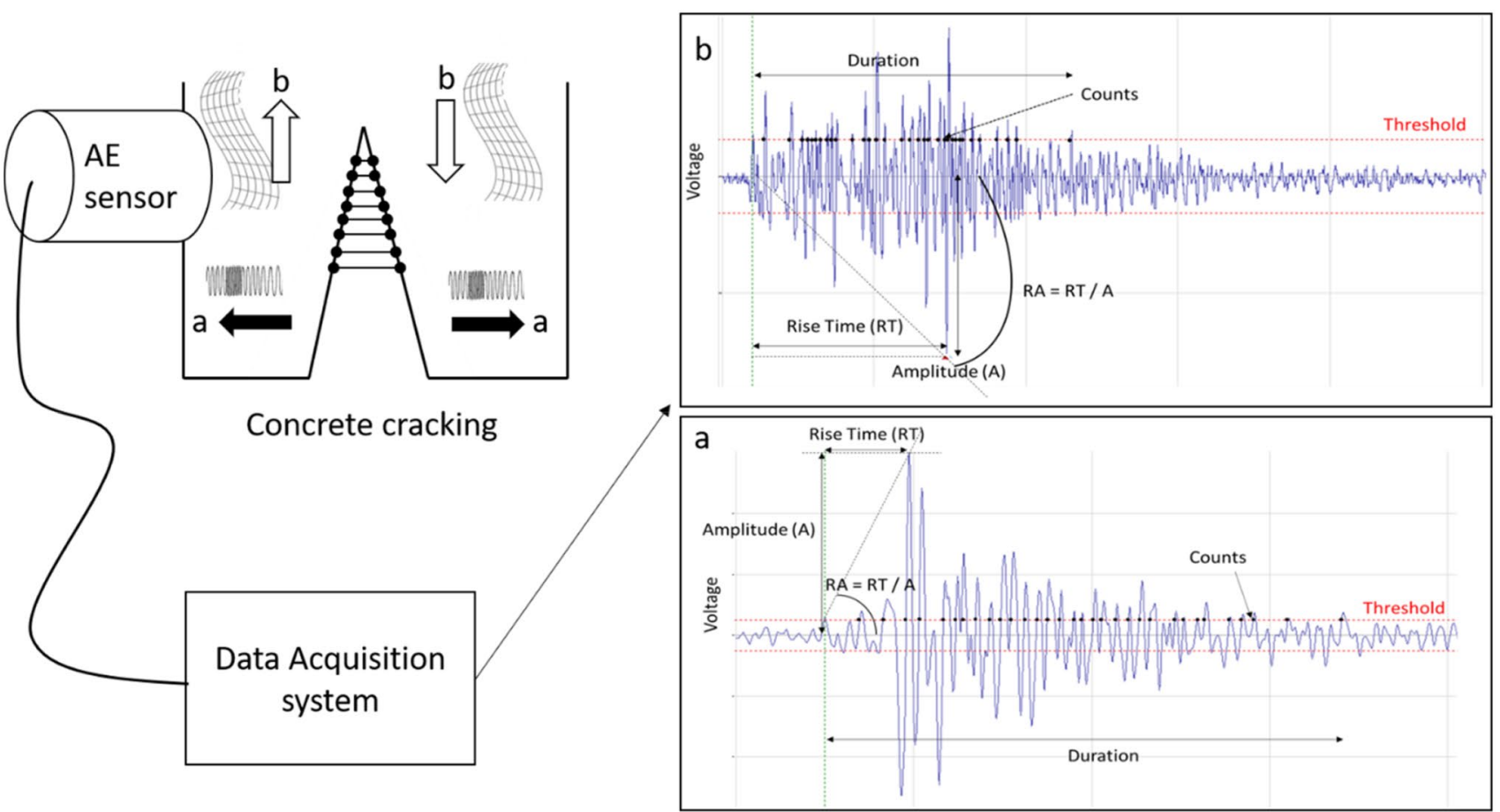

Fig. 6 AE features during cracking process of concrete

waves of large amplitude and frequency, faster than any other wave type, and the resulting rise time is short (Fig. 6a). For shear cracks, the major part of generated waves is $\mathrm{S}$-waves. The maximum amplitude arrives later than the first arrivals giving longer rise time (Fig. 6b).

Crack classification into tensile mode and shear mode was estimated using a correlation of AF variation versus RA value, which is equal to the rise time divided by amplitude expressed in ms/V (Eq. 1):

$\mathrm{RA}=\frac{\text { Rise time }}{\text { Amplitude }}$.

The cracking behavior of concrete can be classified into tensile mode when high AF is detected with low RA value [46-50]. It occurs when cracks are nucleated and opened. Shear cracking mode is characterized by high RA value and low AF, and it is detected with the fretting or sliding of existing cracks.

\section{5 $b$-value analysis}

The $b$-value is a statistical method used to evaluate AE amplitude-frequency distribution. The $b$-value is increasing with the increase of the proportion of $\mathrm{AE}$ events with low amplitudes and decreasing when the proportion of $\mathrm{AE}$ events with high amplitude is increasing. The emergence of microcracks generates a large number of AE events with low amplitudes, so the $b$-value is high. While the formation of macrocracks generates a large number of AE events with high amplitudes, the $b$-value is small. Therefore, changes of $b$-value are a suitable reference to analyze the cracking process of concrete [51].

The $b$-value analysis was first established by Gutenberg-Richter in 1949 [52], with their law stipulating that microcracks generate many hits of small amplitude, while macrocracks generate few hits of large amplitude. The Gutenberg-Richter relation is presented in Eq. 1 in terms of AE parameters.
Table 2 Quantitative result analysis [24, 53]

\begin{tabular}{ll}
\hline$b$-value & Description \\
\hline$[1,1.2]$ & The channel is very near to a large crack or macrocracks are forming \\
{$[1.2,1.7]$} & Cracks are uniformly distributed, and macrocracks are stable \\
$>1.7$ & Microcracks are dominant or macrocracks are opening \\
\hline
\end{tabular}


$\log _{10} N=a-b\left(\frac{A_{\mathrm{dB}}}{20}\right)$,

where $N$ is the number of $\mathrm{AE}$ hits with amplitudes greater than $A_{\mathrm{db}}, A_{\mathrm{db}}$ is the amplitude in $\mathrm{dB}$, a is an empirical constant, $b$ is the $b$-value.

Table 2 summarizes the type of cracking and cracking process based on $b$-value variation, according to studies performed on rock mechanics [53] and RC girders by [24].

\section{Results}

\subsection{Pencil break results}

Pencil lead break testing was performed after setting up the monitoring system to evaluate AE activity under traffic and calculate the velocity of stress waves. AE events are simulated by pencil lead breaks. Simulations were repeated to record both longitudinal and surface waves.

The simulated events were localized using AEwin program, in which the velocity was varied with each simulation to obtain the exact location of the simulated AE event. Moreover, time-domain interpretation of $\mathrm{AE}$ events was carried out to calculate stress wave velocity based on first arrivals of longitudinal waves, which were clearly observed. Stress wave velocity is found to be equal to $3400 \mathrm{~m} / \mathrm{s} \pm 100 \mathrm{~m} / \mathrm{s}$ based on event localization and time-domain interpretation. Therefore, the 60-year-old concrete can be considered in a "good condition" [43].
Data of pencil lead break testing was used to identify classes of AE data. The characteristics of generated acoustic signals in solids during the formation of cracks are similar to the generated acoustic signals due to pencil breaks [54]. AE features collected during $3 \mathrm{~min}$ of pencil lead break testing under regular traffic was classified into two groups as it is illustrated in Fig. 7. The absolute energy, duration, and Pcount are plotted versus the amplitude for the 4301-recorded hits from the 24 channels.

The AE activity due to pencil break test is characterized by high amplitudes $(>80 \mathrm{~dB})$, and high absolute energy $\left(>10^{6} \mathrm{aJ}\right)$, low durations $\left(<10^{4} \mu \mathrm{s}\right)$, and low counts to peak, while the AE activity due to traffic presents lower absolute energy and amplitudes.

The AE activity due to traffic and the one due to pencil break that is similar to crack-like signals are forming two visible clusters. It can be concluded that no cracking formation is present in the slab during the test.

This result is based on data recorded for 3 min considering only surface simulations and can thus not be conclusive about the condition of the slab. Therefore, a detailed investigation of the annual variations of $\mathrm{AE}$ features is performed.

\subsection{AE features}

$\mathrm{AE}$ events were present during the passage of vehicles, and after the passage of heavy trucks and rarely during the absence of traffic. The 24 channels had recorded a total of 47,640,543 hits during the period of monitoring, from $14 / 03 / 2019$ to $14 / 03 / 2020$. The acoustic emission activity
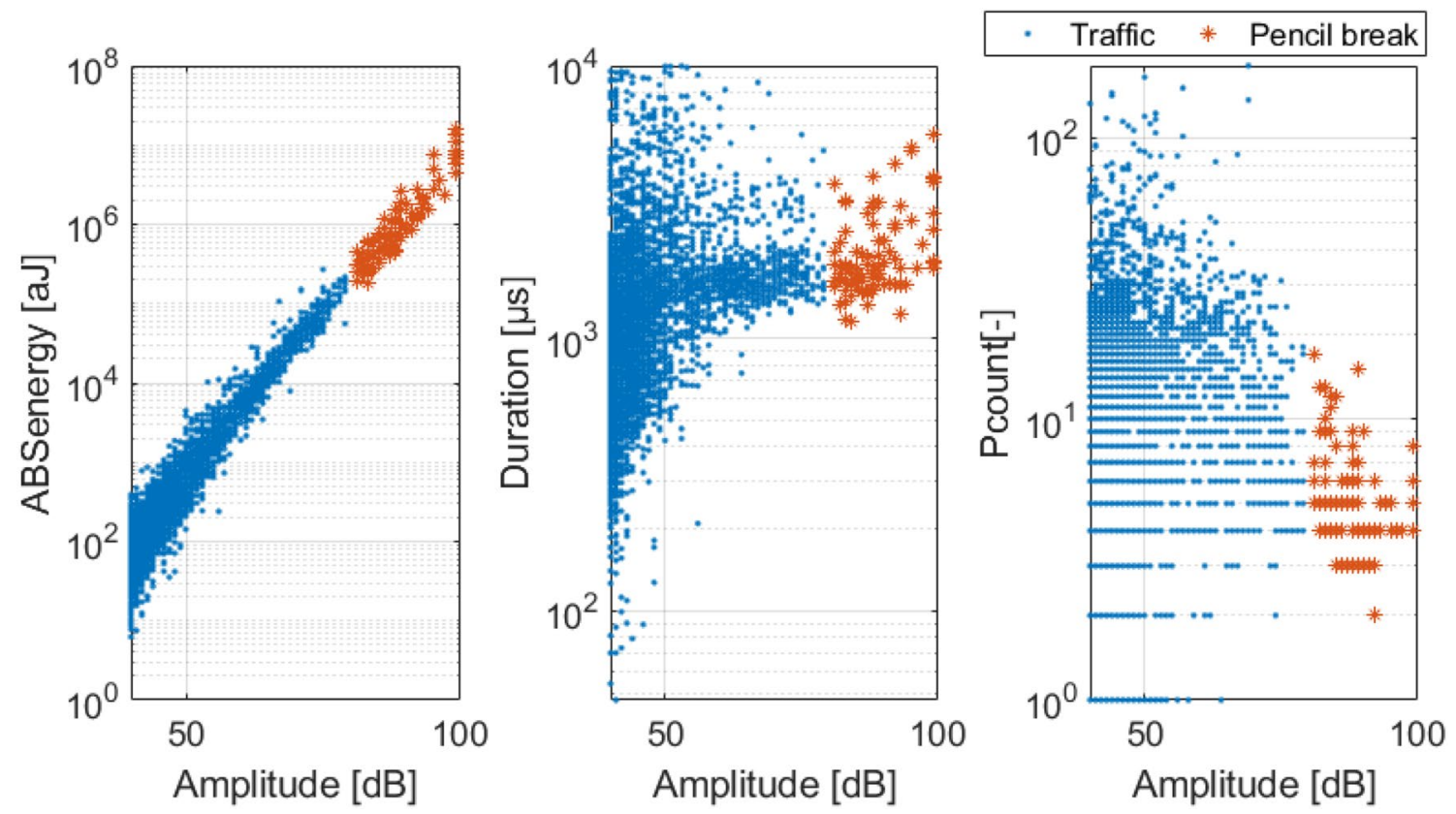

Fig. 7 Results of pencil break test under traffic 
in concrete is due to the principal source associated with concrete cracking and secondary sources including friction, opening, and closure of existing cracks.

Hits characterized by high energy $\left(>10^{6}\right.$ aJ) are mostly related to AE activity due to concrete cracking [55].

A total of $1033 \mathrm{AE}$ hits with absolute energy higher than $10^{6} \mathrm{aJ}$ and amplitudes higher than $75 \mathrm{~dB}$ were recorded for channels at the mid-span. It can be argued that the cracking activity in concrete is active, but its evolution in time is very slow, i.e. $1.6610^{-4} / y e a r$ which corresponds to the ratio of hits with the high amplitude-energy and the number of the total AE hits. The other AE events are mostly due to crack movement at the level of fracture zone and to friction, opening, and closing of existing cracks.

The annual variation of AE features gives qualitative indications about the condition of concrete. In the following section, $\mathrm{AE}$ features were analyzed along with temperature and strain variations, using the input parameters to evaluate the influence of traffic and temperature on crack process and investigate the source of AE activity.

\subsection{AE features and temperature}

Figure 8 presents the annual variation of the temperature of concrete, with the AE features of Channel 6 and the strain of longitudinal and transverse rebars at the mid-span. To illustrate the annual effect of temperature, the moving average of the maximum values of the AE features was calculated and presented as a thick line. Similarly, the moving average of thermal strain $\epsilon_{\mathrm{T} / \text { longitudinal }}$ and $\epsilon_{\mathrm{T} / \text { transverse }}$ was plotted, respectively, for longitudinal and cross sections.

The maximum values of amplitude, absolute energy, and Pcount were decreasing with the increase in temperature
Fig. 8 Annual variation of amplitude, absolute energy, AF and Pcount of Channel 6, and longitudinal and transverse thermal strain, and temperature of concrete
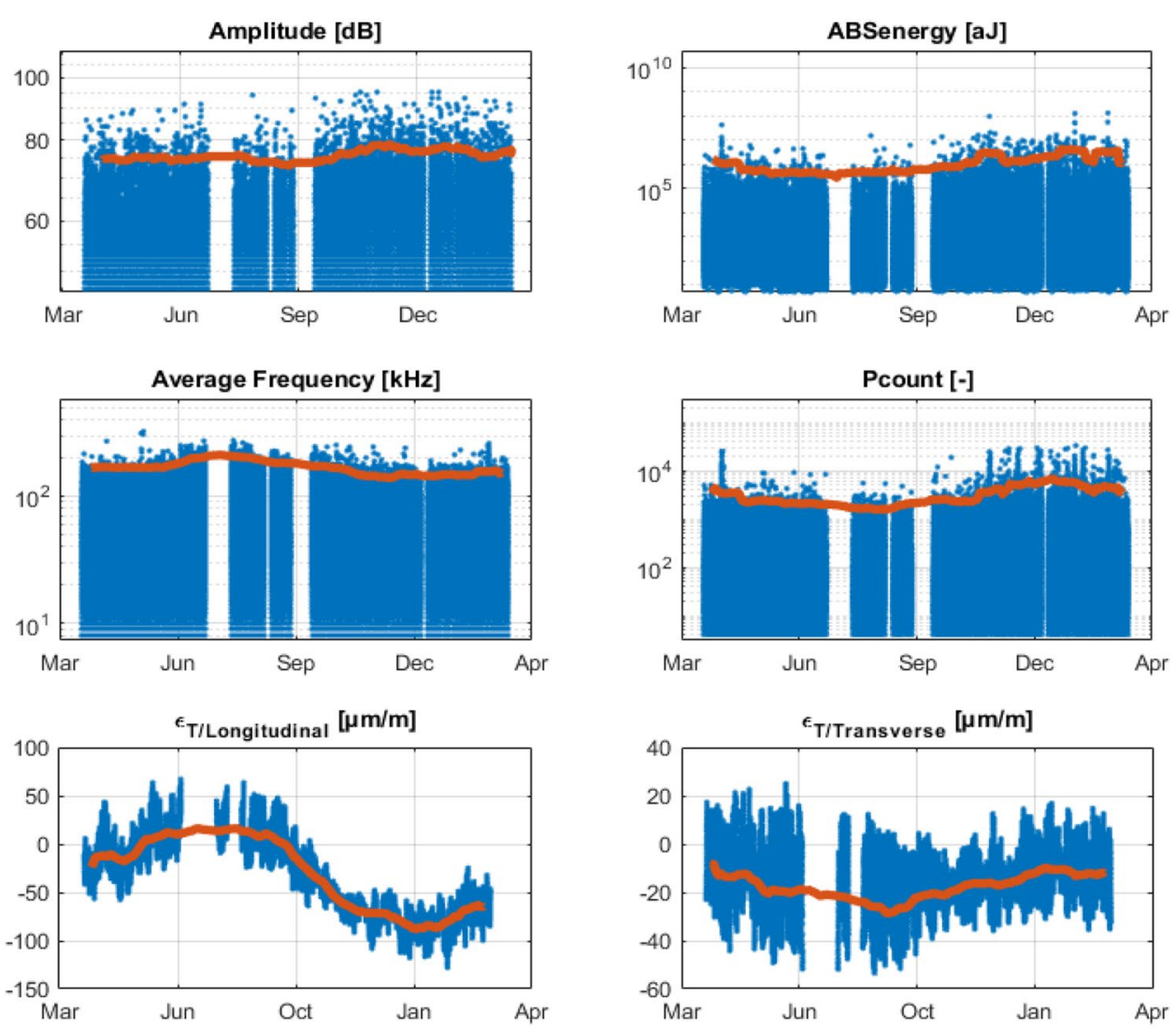

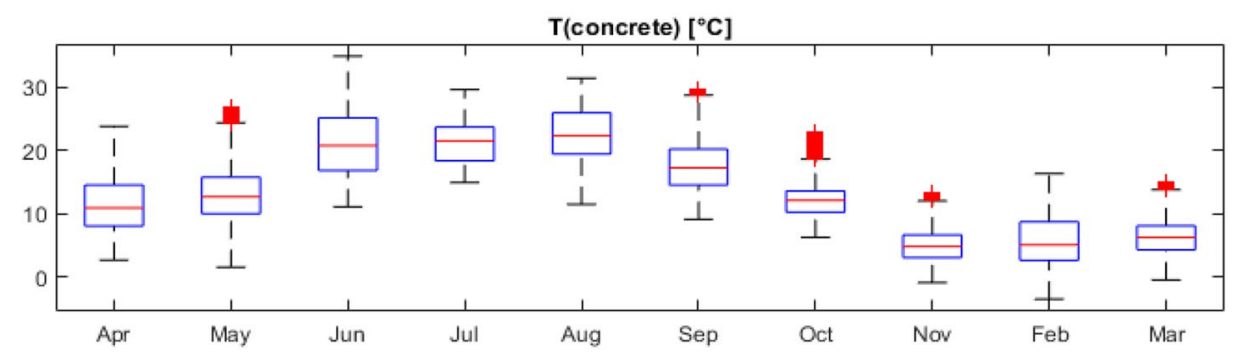


while the AF was increasing. Similar observations were found for daily cycles.

The increase in temperature generates an increase of longitudinal thermal strain and a decrease of transverse thermal strain due to material expansion and boundary conditions. Thermal variation is, therefore, inducing daily and seasonal microcrack movement and internal microcracking. Microcracks are opening and closing according to their orientationregarded longitudinal and transverse sections. The opening and closing of microcracks are cyclic following the daily and seasonal temperature variations which demonstrate the stability of the cracking activity in the RC slab.

The energy required to open the microcracks under traffic loading is less during summer if they are opening with temperature increase and their size is assumed to be constant. This explains the decrease of the calculated values of the absolute energy, amplitude, duration, and Pcount with temperature increase.

The observed trend of thermal variation of $\mathrm{AE}$ features was different when the temperature of concrete is less than zero degrees Celsius. This can be due to the thaw-freeze of concrete. The ice formation can be initiated in pores with interstitial solution for low-temperature conditions. The pore solution can freeze and highly porous border zones around aggregate might be separated from the ice front through smaller cement matrix pores leading to high hydrostatic pressure [56]. This pressure can create the opening and closing of existing microcracks, generating more AE events under low temperatures.

\subsection{AE features and strain}

AE response was evaluated along with strain variation of rebars on the same time scale. AE features were analyzed for randomly selected vehicles with different weights and positions. The method used to calculate the weight and the position of the vehicles is based on strain measurements and can be found in [38].

An example of $\mathrm{AE}$ response and strain variation is presented in Fig. 9 when a light vehicle and a heavy truck crossed the road viaduct separately. The light vehicle had a weight of $16.2 \mathrm{kN}$ and it was crossing the viaduct from Travers direction, while the heavy truck had a weight of 330 $\mathrm{kN}$ with three axles and it was crossing the viaduct from Neuchâtel direction. The response of Channel 6 was plotted with the variation of the longitudinal strain at mid-span.

The hits generated by the heavy truck were characterized by lower values of absolute energy and Pcount and higher values of $\mathrm{AF}$, while no difference was observed for duration and amplitude.

Light-vehicle passage lasts less than $1 \mathrm{~s}$, generating 8 hits in Channel 6. The released energy is concentrated at the beginning of the passage where the maximum compression of longitudinal rebar and the maximum tension of transverse rebar are occurring.

Truck passage lasts $2 \mathrm{~s}$ generating 12 hits in Channel 6 . The released energy is distributed among the axles and reaches the maximum with the passage of the last one. The stored elastic strain energy is first steadily built up with each axle until it reaches the maximum with the last axle. This observation was valid also for many other passages.

By analyzing many hits due to both light vehicles (weight $<35 \mathrm{kN}$ ) and trucks (weight $\geq 35 \mathrm{kN}$ ), it was observed that the AE activity due to light vehicles crossing the road-viaduct was not detected by all Channels, while $\mathrm{AE}$ due to trucks was detected by all the Channels during loading and for some heavy trucks also during unloading. This can be due to the process of opening and closing of microcracks during and after the passage. The maximum values of absolute energy and amplitude were recorded when the maximum strain is reached in longitudinal and transverse rebars as shown in Fig. 9.

The generated hits that correspond to light vehicles crossing the viaduct were characterized by higher values of absolute energy, Pcount and duration, and lower values of $\mathrm{AF}$ compared to heavy trucks. In fact, light vehicles generate a low number of hits where the total energy is concentrated giving high values of absolute energy per hit. Moreover, the speed of light vehicles is generally higher than the one for trucks, which can generate hits containing more than one $\mathrm{AE}$ event, which gives higher values of duration.

The crossing of heavy trucks generates lower absolute energy and lower duration per hit. Trucks have lower speeds and many axles that generate many hits one after the other. The absolute energy is defined as the time integral of the square of the signal voltage. The lower values of the energy calculated when trucks were crossing the road-viaduct can, therefore, be due to low values of duration.

This observation was demonstrated by analyzing the high values of absolute energy that corresponds to light vehicles. They were found to be related to events with high durations and normal amplitudes. The variation of absolute energy should be evaluated along with the variation of duration. Moreover, this energy is split into local energies since each axle is generating many events. The distribution of the total energy is giving lower values of energy per hit compared to the ones produced by light vehicles concentrated in one or two hits. This means that the speed of loading and the number of axles are influencing the detected AE energy.

$\mathrm{AF}$ values for trucks were higher because the generated AE signals cross the detection threshold many times compared to the AE signals generated by light vehicles. In contrast, both amplitude and Pcount variations present different trends for both light vehicles and trucks.

The presented truck in Fig. 9 was crossing the road viaduct from Neuchâtel direction, while the light vehicle 

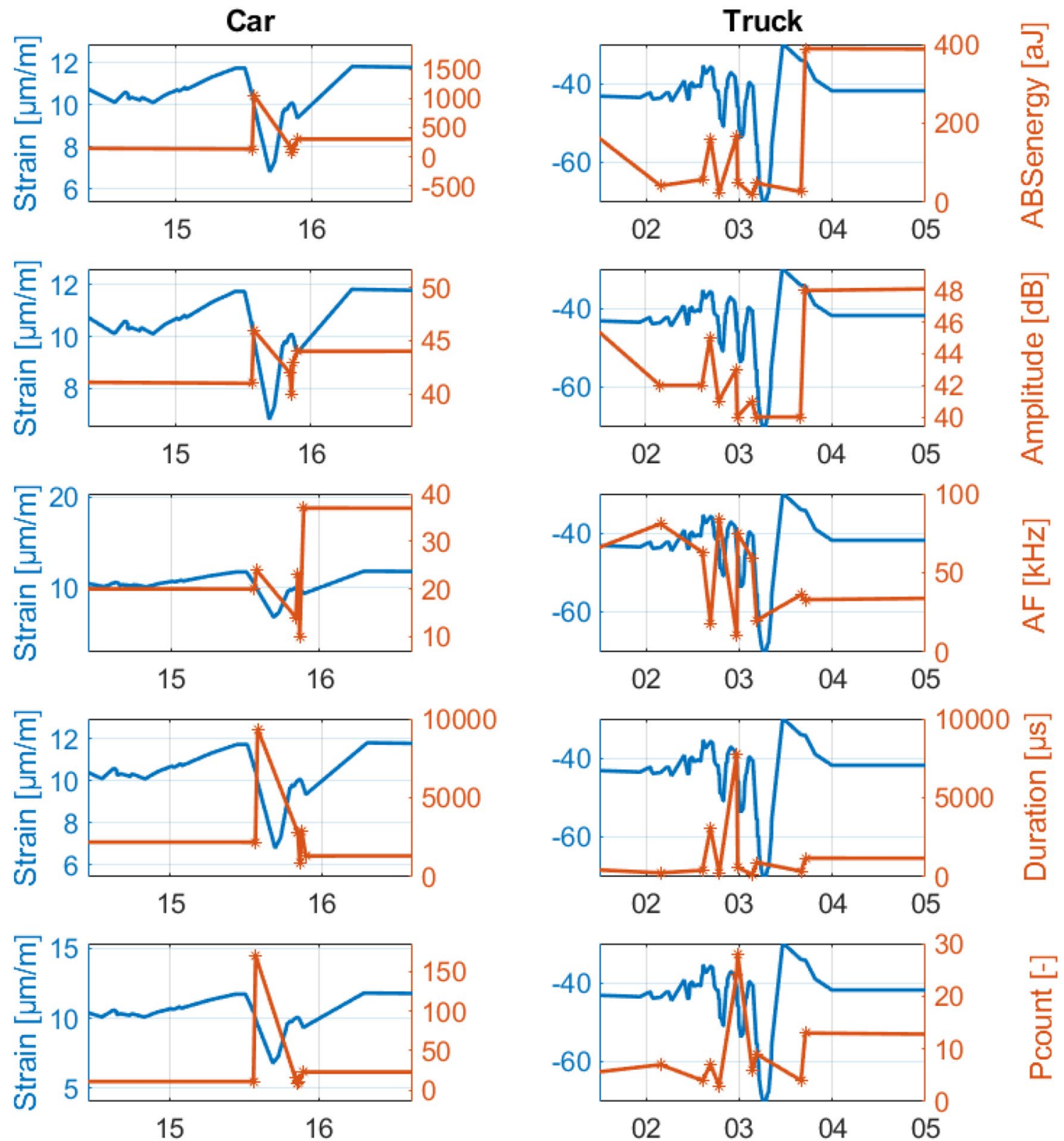

[s]

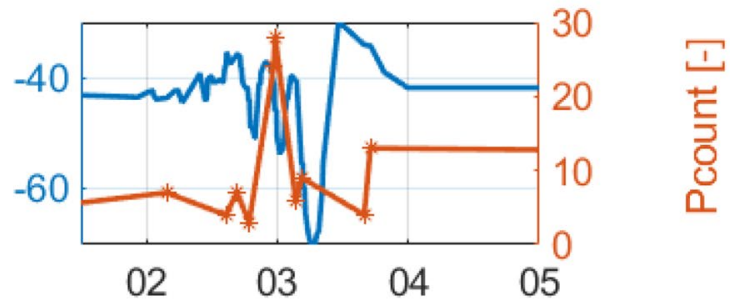

[s]

Fig. 9 Variation of longitudinal strain and AE features of Channel 6 during the passage of a light vehicle and a heavy truck

was crossing from Travers direction. The annual mean and maximum of AE features were evaluated according to the direction of crossing. It was found that the Pcount and duration were higher for vehicles in the Neuchâtel direction, while absolute energy, amplitude, and AF were independent on the position of the vehicles. It can be concluded that amplitude, absolute energy, and AF depend more on the weight while duration and Pcount are related to the position and the weight of the vehicles and the position of the AE sensors.

\subsection{Correlations and statistics}

The number of AE hits detected by every channel is different for the same conditions of loading. The number of hits is a simple method to evaluate the AE activity near the sensors. The presence of many hits can indicate an active cracking process near the channel, while small number of hits indicates a stable condition. In Fig. 10, the generated AE hits for the 24 channels are presented. 


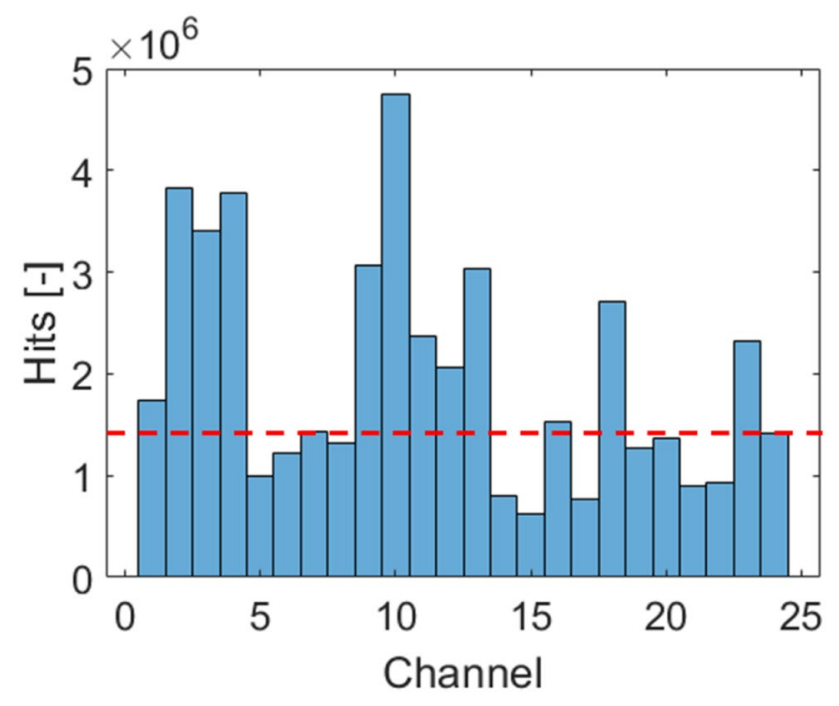

Fig. 10 Annual AE hits for the 24 channels
The recorded hits in channels $2,3,4,9,10,13,18$, and 23 were significantly higher. This observation can be attributed to AE source originating from small relative displacement between the slab and the girder. Furthermore, channels near the slab-girder connection (i.e. Channels 9, 10, 18, 13, 2, 23) were detecting almost similar number of hits, and high values of absolute energy ( $\left.>10^{7} \mathrm{aJ}\right)$, duration, and Pcount. Channels near the support (Channels 2, 3,4) were detecting similar number of events and higher absolute energy, while channels in the mid-span were detecting lower number of events and lower absolute energy (mostly $<10^{6} \mathrm{aJ}$ ).

The variation of $\mathrm{AE}$ features presents apparent similarities and differences regarding the position of sensors which can be due to the existence of different sources of AE. Therefore, four grids were defined to evaluate AE activity in different locations and address the scatter of AE response.

Grid 1 comprises Channels 5, 6, 7, 17, 21, 22, to evaluate the AE activity in the mid-span. Grid 2 comprises Channels $2,9,10,13,18,23$ to evaluate the condition of the
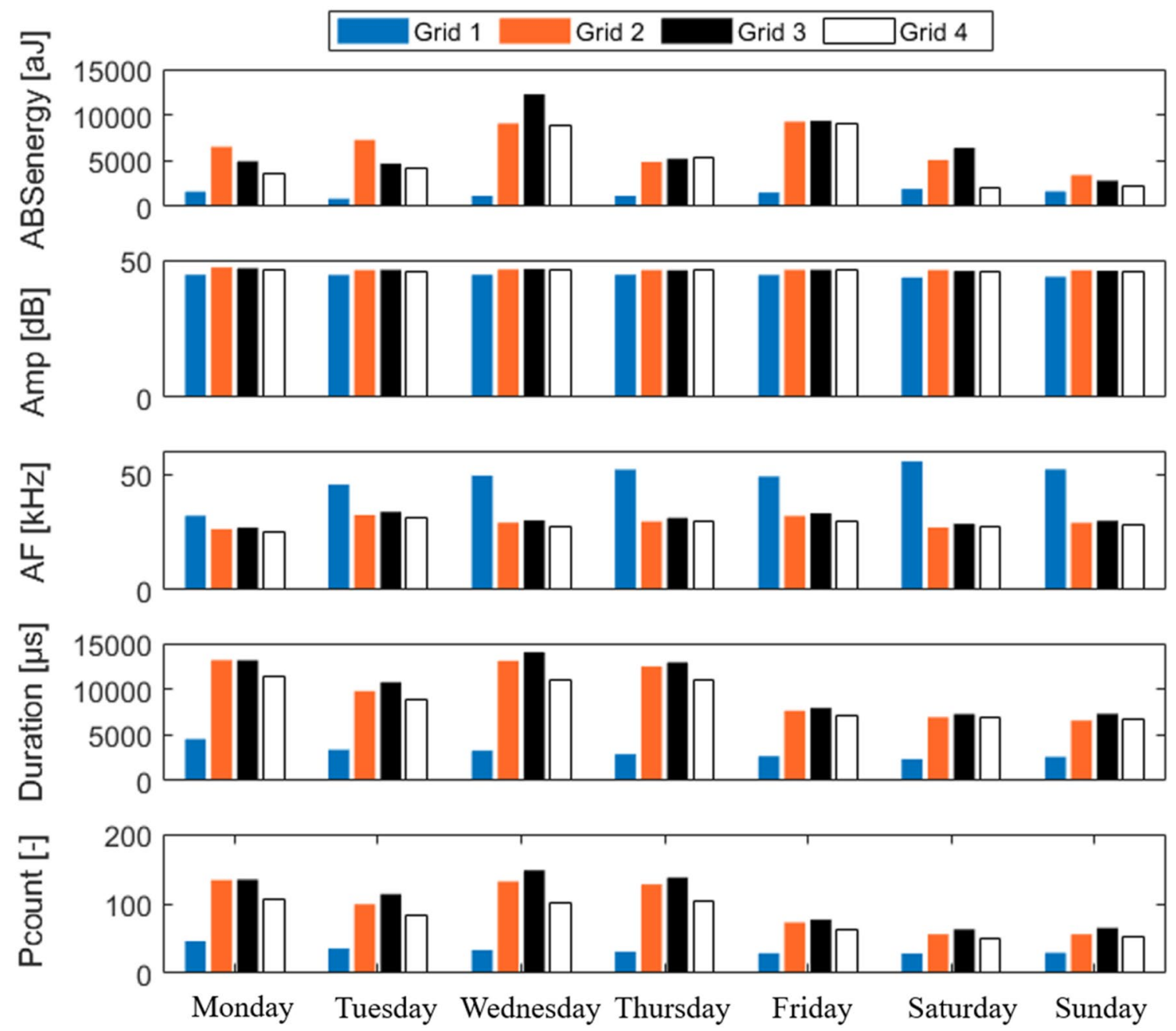

Fig. 11 Variation of AE features per grid for one week 
Table 3 Number of light vehicles $(<3.5 \mathrm{t})$ and heavy trucks $(\geq 3.5 \mathrm{t})$

\begin{tabular}{lccccccr}
\hline Days & Monday & Tuesday & Wednesday & Tuesday & Friday & Saturday & Sunday \\
\hline Light vehicles & 6596 & 6552 & 6579 & 6601 & 6582 & 6783 & 6811 \\
Heavy trucks & 227 & 271 & 244 & 222 & 241 & 40 & 12 \\
\hline
\end{tabular}

Table 4 RA and AF values for cracking mode classification

\begin{tabular}{lll}
\hline Cracking mode & AF & RA \\
\hline Tensile mode & $>50 \mathrm{kHz}$ & Left side of the line \\
Mixed mode & $\leq 50 \mathrm{kHz}$ & $\leq 2500 \mathrm{~ms} / \mathrm{V}$ \\
Shear mode & Right side of the line & $>2500 \mathrm{~ms} / \mathrm{V}$ \\
\hline
\end{tabular}

connection slab-girder. Grid 3 comprises Channels 2, 3, 4 near the support, and Grid 4 comprises Channels 13, 14, 15, 16 near the articulation.

The daily mean of the AE features for the week 06/05/2019-12/05/2019 was calculated for each grid and illustrated in Fig. 11, Table 3 with the number of light vehicles and trucks per day.

The daily mean values of amplitude were varying in the range of 43-50 dB for all grids and did not present significant changes. While the difference between grids was more apparent for absolute energy, duration, and Pcount, the highest values were recorded in Grids 2 and 3 and in Grid 1 for the AF.

The daily mean values depend on the number of vehicles and their type. AF was higher during weekends while the rest of AE features were higher during weekdays where the number of heavy trucks was more pronounced. Similar variations were observed for other weeks. Duration and Pcount on Friday show the same tendency with weekend. This can be due to the number of trucks with weights between $3.5 \mathrm{t}$ and $10 \mathrm{t}$, which are more frequent on Friday. These trucks have different speed and number of axles that are influencing the duration of the detected hits and the number of counts.

These weekday variations are due to the opening and closing of microcracks with the passage of heavy trucks. The difference between channels in mid-span and channels near the articulation, support and connection slab-girder demonstrates the existence of a second source of AE, mostly due to friction between different elements. In the following section, the cracking process will be classified into tensile and shear modes to clarify the source of AE activity for each grid.

\subsection{Characterization of cracking}

$\mathrm{AF}$ and RA values were calculated from the moving average of $100 \mathrm{AE}$ Hits. The ratio of the abscissa scale to the

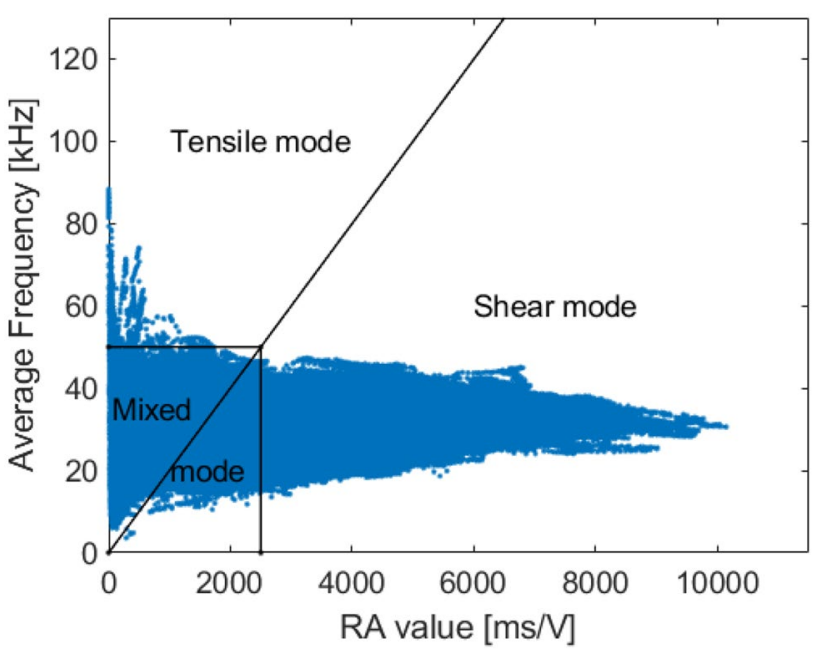

Fig. 12 RA value analysis for Grid 1 at mid-span

ordinate scale is set to 50 according to the recommendations of RILEM TC 212-ACD [49]. Aggelis [47] has shown that tensile matrix cracking of concrete results in AF higher than approximately $50 \mathrm{kHz}$, which corresponds to a RA value of $2,500 \mathrm{~ms} / \mathrm{V}$. This value of AF is assumed to be valid for the case study to classify cracking modes. Classification of AE events into tensile mode, shear mode, and mixed mode was,, therefore, determined based on values presented in Table 4 , Fig. 12.

It is estimated that pure tensile mode is due to the expansion of microcrack region, while mixed mode is due to the opening and closing of existing microcracks. Shear mode is assumed to be due to friction between existing microcracks, friction between the slab and the girder, and friction at the level of the support and articulation. Table 5 presents the obtained percentage of the cracking modes for each grid.

At mid-span, $1 \%$ AE events were classified as shear mode and $4 \%$ as tensile mode, while $95 \%$ was classified as mixed mode. This means that the AE activity is generated mostly by the opening and closing of existing microcracks and friction at the level of the fracture process zone, while $4 \%$ of the detected AE activity is due to the expansion of microcracks.

Shear mode was higher near the support and the articulation and near the slab-girder connection, while tensile mode was lower. This confirms that $14-20 \%$ of the generated AE 
Table 5 Cracking mode classification per grid

\begin{tabular}{lllcr}
\hline & $\begin{array}{l}\text { Tensile } \\
\text { mode }(\%)\end{array}$ & Mixed mode $(\%)$ & Shear mode (\%) & No. samples \\
\hline Grid 1 (mid-span) & 3.55 & 95.16 & 1.29 & $6,238,729$ \\
Grid 2 (connection slab-girder) & 0.19 & 81.44 & 18.37 & $19,727,020$ \\
Grid 3 (support) & 0.19 & 80.08 & 19.73 & $11,004,243$ \\
Grid 4 (articulation) & 0.28 & 85.92 & 13.80 & $5,989,317$ \\
\hline
\end{tabular}

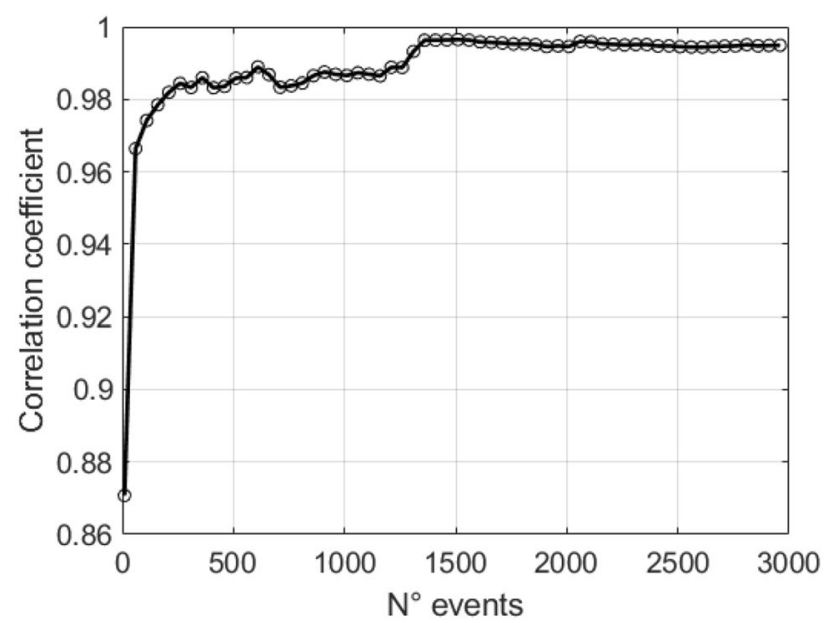

Fig. 13 Correlation between the logarithmic frequency $\log _{10} N$ and amplitude $A_{\mathrm{db}}$

events for Grids 2-4 are due to the friction between the slab and the girder and at the level of the articulation and the support, while the expansion of microcracks presents less than $3 \%$ of the total AE activity.

The opening and closing of existing microcracks are estimated to be the main source of the AE activity along the slab. To investigate with more detail the nature of cracking process, $b$-value analysis is performed in the following section.

\section{$5.7 b$-value analysis}

The $b$-value analysis was performed for the $\mathrm{AE}$ events recorded during one year of continuous monitoring under traffic and environmental loading. Linear least square method was used to calculate the slope of amplitude-frequency distribution. It is, therefore, necessary to select appropriate number of AE hits. When the selected number is small, the oscillations are too strong, masking the general trend. If the number is too large, any small incidence producing just a small number of events would be undermined in the average of the large events. During laboratory tests, it was found that 50 is an appropriate sample size to perform $b$-value analysis [57]. However, such recommendations are not available for $\mathrm{AE}$ events generated under real traffic and environmental conditions.

To determine the proper number of AE events for $b$-value calculations, correlation coefficients between the logarithmic frequency $\log _{10} N$ and amplitude $A_{\mathrm{db}}$ were calculated and presented in Fig. 13. It was found that in all channels, the relation between the logarithmic cumulative frequency and amplitude gives proper straight lines when the number of $\mathrm{AE}$ events is larger than 1500 .
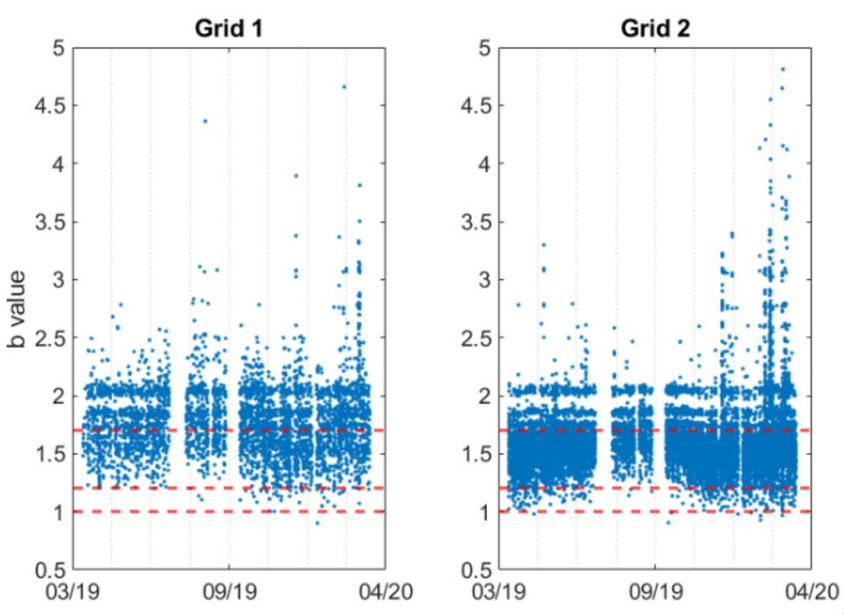
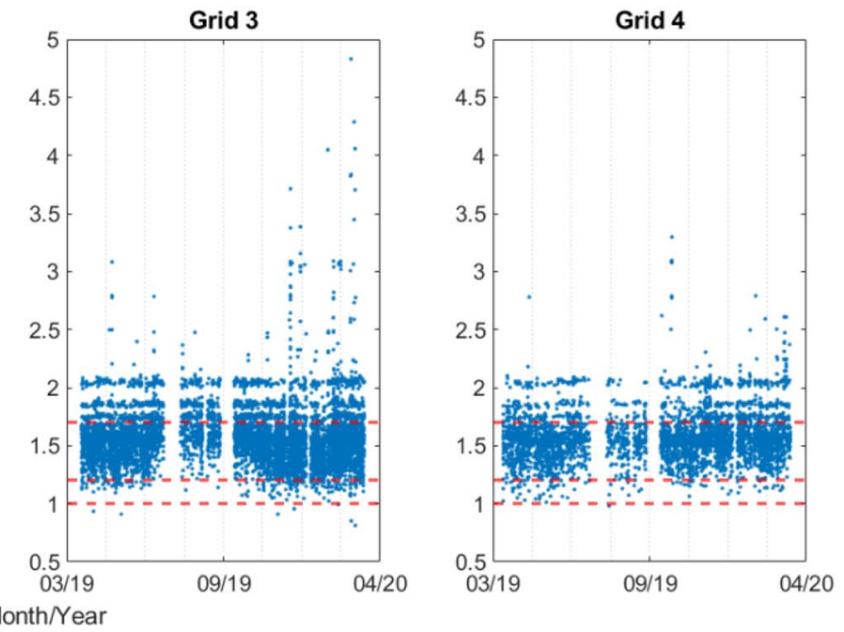

Fig. $14 b$-value based on 1500 events 

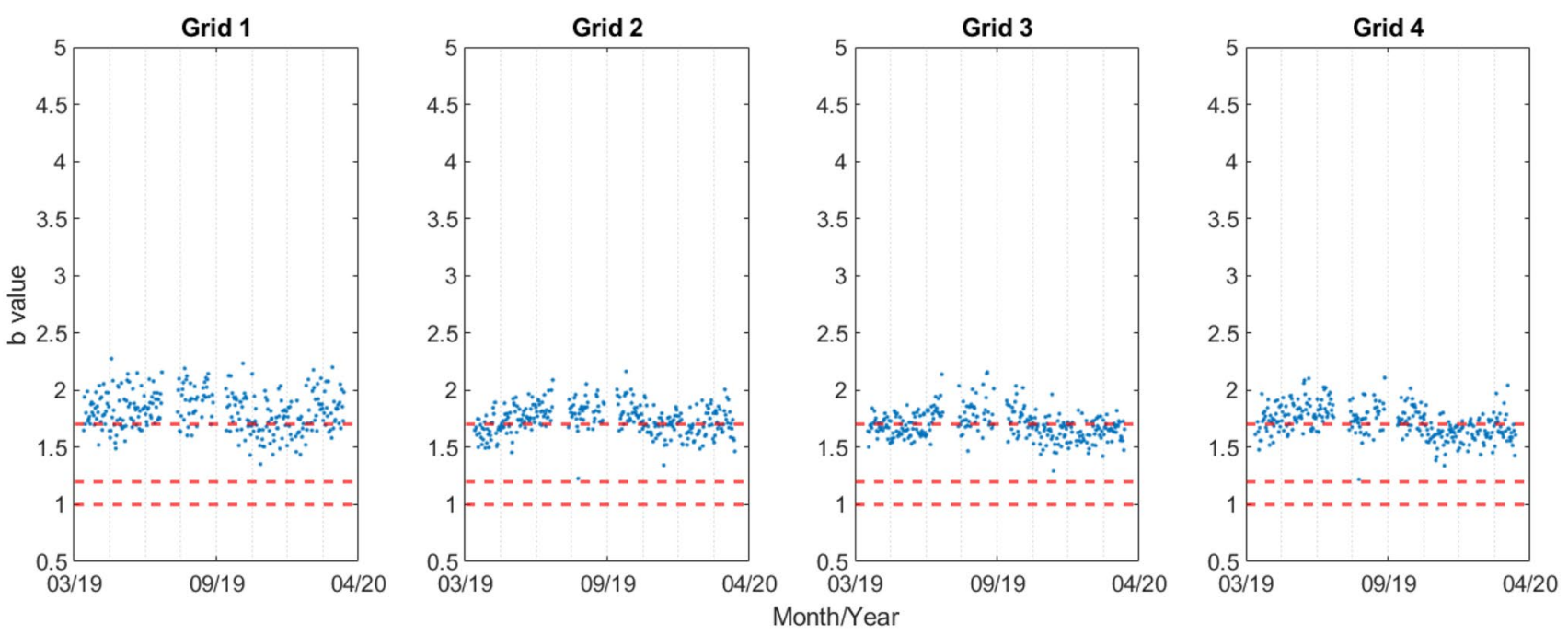

Fig. 15 Daily $b$-values for the period of monitoring 14/03/2019 to 14/03/2020

Therefore, $b$-values were calculated using two sets of amplitude-frequency based on least squares curve-fit: amplitudes due to 1500 successive hits (Fig. 14) and daily amplitudes (Fig. 15). The limits of $b$-value ranges $(1,1.2$, and 1.7) presented in Table 2 are plotted with red dashed lines.

The calculations based on 1500 events show different trends of $b$-value and higher values for the four grids, implying changes in the range $[1,5] .66 \%$ of the values were in the range $[1.2,1.7]$ indicating uniform distribution of microcracks (39\% for Grid 1,71\% for Grid 2,75\% for Grid 3, and 77\% for Grid 4). The source of the AE events related to these values is, therefore, the movement of the two crack surfaces of existing microcracks during traffic and environmental loading or friction at the level of fracture process zone, while the existing macrocracks are stable.

The few values in the range $[1,1.2]$ were about $2 \%$ of the total values. They are due to AE events recorded during low traffic periods, and they cannot refer to any cracking process, while the values higher than 1.7 were about $60 \%$ for Grid $1,27 \%$ for Grid 2, 23\% for Grid 3, and 21\% for Grid 4. The values present stable variation in the range $[1.7,2.5]$ for the four grids with few values varying between 2 and 5 . Values higher than 1.7 indicate the dominance of microcracks or the formation of macrocracks.

This indication is based on laboratory testing of RC girders subject to higher load magnitude, different from service loading. The loading process can change the AE response and make the direct comparison between laboratory tests and in-situ tests difficult. This was reported by [29] who had performed cyclic loading tests on RC girders using a loading protocol that is representative of realistic service-level loading. They found that defining absolute critical $b$-value can be unmeaning and that parallel observation of structural performance is needed. They have suggested analyzing the lowest $b$-values.

The lowest $b$-values were in the range of a uniform distribution of microcracks and they were following temperature variation. Hits that were giving low $b$-values $(<1)$ or high $b$-values $(>3)$ were generally associated with low traffic periods during nights or weekends. Besides, $b$-value trends were presenting stable annual variation and no visible active macrocracks were detected in the RC slab. These results show that the RC slab has uniform microcracks and stable macrocracks. $b$-value analysis was also performed for the defined grids using daily values of amplitude-frequency (Fig. 15).

The general trend of $b$-value is more visible with the daily variations. The annual $b$-value was varying in the range $[1.5$, 2] following thermal variations. Values less than 1.2 were about $16 \%$ of the total values for the four grids, while values between 1.2 and 1.7 were about $50 \%$ of the calculated values. Therefore, the AE activity in concrete is mainly due to the opening of microcracks during summer and closing during winter. The cyclic annual trend of $b$-value demonstrates the stability of existing cracks. $b$-value range implies the existence of uniformly distributed microcracks and stable macrocracks. Values higher than 1.7 were about $22 \%$ for Grid 1, 30\% for Grid 2, 45\% for Grid 3 and 38\% for Grid 4. This implies that microcracks are dominant or macrocracks are opening. Those variations are present during summer when existing microcracks and stable macrocracks are opening with the increase in temperature. 


\section{Conclusions}

The paper presents the parametric and statistical analyses carried out on $\mathrm{AE}$ data and strain measurements recorded during 1 year of continuous monitoring of an RC bridge deck slab under traffic loading and environmental changes.

Despite the challenges of on-site assessment of bridges, the presented monitoring approach demonstrated that assessment of the structural response and characteristics under operational loading and environmental changes are feasible and can be done within reasonable postprocessing work. Five main conclusions are drawn:

The instrumentation, calibration, and synchronization of the used techniques present solid recommendations for the assessment of RC road bridge deck slabs using $\mathrm{AE}$ and strain measurements.

The presented monitoring data and applied processing methods are appropriate to quantify the influence of environmental and operational conditions on the structural behavior of road bridge elements.

The variability of AE features under traffic and environmental changes have been determined using 1 year of continuous monitoring. The findings should be considered when performing short-term monitoring or translating AE laboratory knowledge to the field.

The structural characteristics, i.e. the condition of the support, the articulation, and the slab-girder connection are affecting differently the AE activity of the nearest sensors. This result allows to assess in time different components of road bridges.

The use of $b$-value analysis and cracking mode classification on long-term monitoring data provides the source and the evolution in time of the cracking activity of concrete, in case operational loading and thermal variations are known.

The cyclic response of AE sensors and strain gauges demonstrates the robustness of the monitoring approach to assess the operational conditions of road bridges. The deployment of the monitoring data using signal-based technique, frequency analysis, and AE localization will be presented in further work.

Acknowledgements This research work was performed within the European project INFRASTAR (infrastar.eu), which has received funding from the European Union's Horizon 2020 research and innovation program under the Marie Skłodowska-Curie grant agreement No. 676139. The grant is gratefully acknowledged.

Funding Open access funding provided by EPFL Lausanne.

Open Access This article is licensed under a Creative Commons Attribution 4.0 International License, which permits use, sharing, adaptation, distribution and reproduction in any medium or format, as long as you give appropriate credit to the original author(s) and the source, provide a link to the Creative Commons licence, and indicate if changes were made. The images or other third party material in this article are included in the article's Creative Commons licence, unless indicated otherwise in a credit line to the material. If material is not included in the article's Creative Commons licence and your intended use is not permitted by statutory regulation or exceeds the permitted use, you will need to obtain permission directly from the copyright holder. To view a copy of this licence, visit http://creativecommons .org/licenses/by/4.0/.

\section{References}

1. Spathelf CA, Vogel T (2018) Fatigue performance of orthogonally reinforced concrete slabs: Experimental investigation. Eng Struct 168:69-81. https://doi.org/10.1016/j.engstruct.2018.04.058

2. Treacy MA (2014) The use of monitored data in the verification of structural and fatigue safety of existing post-tensioned concrete highway bridges. Ph.D. Thesis Éc Polytech Fédérale Lausanne

3. Fehlmann P (2012) Zur Ermüdung von Stahlbetonbrücken. Ph.D. Thesis. IBK Ber 335

4. Herwig A (2008) Reinforced Concrete Bridges under increased Railway Traffic Loads - Fatigue Behaviour and Safety Measures. Ph.D. Thesis Éc Polytech Fédérale Lausanne

5. Schläfli M (1999) Ermüdung von Brückenfahrbahnplatten aus Stahlbeton. Ph.D. Thesis Éc Polytech Fédérale Lausanne, p 128

6. Zhang J, Bai B, Zhao S, Zuo X (2019) Fatigue characteristic and life test of reinforced concrete $\mathrm{T}$ girders under cyclic loading. IOP Conf Ser Earth Environ Sci 358:052041. https://doi. org/10.1088/1755-1315/358/5/052041

7. Rocha M, Brühwiler E (2012) Prediction of fatigue life of reinforced concrete bridges using Fracture Mechanics. In: Proc. Bridge Maint. Saf. Manag. Resil. Sustain. https://infoscience.epfl. ch/record/180270. Accessed 2 Apr 2020

8. Schläfli M, Brühwiler E (1998) Fatigue of existing reinforced concrete bridge deck slabs. Eng Struct 20:991-998. https://doi. org/10.1016/S0141-0296(97)00194-6

9. Perdikaris PC, Beim S (1988) RC bridge decks under pulsating and moving Load. J Struct Eng 114:591-607. https://doi. org/10.1061/(ASCE)0733-9445(1988)114:3(591)

10. Okada K, Okamura H, Sonoda K (1978) Fatigue failure mechanism of reinforced concrete bridge deck slabs. Transp Res Record 664:136-144. http://onlinepubs.trb.org/Onlinepubs/ trr/1978/664/664v1-018.pdf

11. Prakash Rao DS, Tamhankar MG, Sharma SP (1983) Literature survey onin situ testing of concrete bridges. Matér Constr 16:457466. https://doi.org/10.1007/BF02476345

12. Scott M, Rezaizadeh A, Delahaza A, Santos CG, Moore M, Graybeal B, Washer G (2003) A comparison of nondestructive evaluation methods for bridge deck assessment. NDT Amp E Int $36: 245-255$

13. Breysse D (2012) Non-destructive assessment of concrete structures: reliability and limits of single and combined techniques: state-of-the-art report of the RILEM technical committee 207INR. Springer, Amsterdam

14. Campbell LE, Connor RJ, Whitehead JM, Washer GA (2020) Benchmark for evaluating performance in visual inspection of fatigue cracking in steel bridges. J Bridge Eng 25:04019128. https ://doi.org/10.1061/(ASCE)BE.1943-5592.0001507

15. Phares BM (2005) 9 - Visual inspection techniques for bridges and other transportation structures. In: Fu G (ed) Inspection and 
monitoring techniques for bridges and civil structures. Woodhead Publishing, Cambridge, pp 166-182

16. Washer G, Moore M, Walther R (1999) FHWA approach for reliability testing of the visual inspection method. In: 1999 New Orleans Structures Congress Structural Engineering Institute of American Society of Civil Engineers, Structural Association of Alabama, National Council of Structural Engineers Associations, Florida Structural Engineers Association, Louisiana Section of ASCE, Baton Rouge Branch of A Structural Engineering Association of American Society of Civil Engineers, Structural Engineers Association of Alabama, National Council of Structural Engineers Associations, Florida Structural Engineers Association, Louisiana Section of ASCE, Baton Rouge. https://trid.trb.org/view/511608

17. Bayane I, Long L, Thöns S, Brühwiler E (2019) Quantification of the conditional value of SHM data for the fatigue safety evaluation of a road viaduct. In: Infoscience. https://infoscience.epfl.ch/recor d/269191. Accessed 31 Jan 2020

18. Shahidan S, Pullin R, Bunnori NM, Zuki SSM (2017) Active crack evaluation in concrete beams using statistical analysis of acoustic emission data. Insight Non Destr Test Cond Monit 59:24-31. https ://doi.org/10.1784/insi.2017.59.1.24

19. Noorsuhada MN (2016) An overview on fatigue damage assessment of reinforced concrete structures with the aid of acoustic emission technique. Constr Build Mater 112:424-439. https://doi. org/10.1016/j.conbuildmat.2016.02.206

20. Elfergani HA, Pullin R, Holford KM (2013) Damage assessment of corrosion in prestressed concrete by acoustic emission. Constr Build Mater 40:925-933. https://doi.org/10.1016/j.conbuildma t.2012.11.071

21. Shiotani $T$ (2012) Recent advances of AE technology for damage assessment of infrastructures. J Acoust Emiss 30. https://www. ndt.net/article/jae/papers/30-076.pdf

22. Wevers M (1997) Listening to the sound of materials: acoustic emission for the analysis of material behaviour. NDT E Int 30:99106. https://doi.org/10.1016/S0963-8695(96)00051-5

23. Felux MW (2017) Acoustic emission monitoring on bridges under regular operating conditions. Ph.D. Thesis. IBK Ber 373

24. IngS C, Main IG, Forde MC (2003) Assessing damage of reinforced concrete beam using " $b$-value" analysis of acoustic emission signals. J Mater Civ Eng 15:280-286. https://doi. org/10.1061/(ASCE)0899-1561(2003)15:3(280)

25. Drouillard TF (1994) Acoustic emission: the first half century. EG and G Rocky Flats, Inc., Golden

26. Asaue TSH, Nishida T, Maeshima T, Tanaka Y (2017) Evolution of fatigue damage in wheel-loading tests evaluated by $3 \mathrm{D}$ elastic-wave tomography. J Disaster Res 12:487-495. https://doi. org/10.20965/jdr.2017.p0487

27. Li S, Shi H, Wu G, Wang D (2017) Application of acoustic emission technique to crack detection of concrete hollow slab bridges. Bridge Constr. https://en.cnki.com.cn/Article_en/CJFDTotalQLJS201705015.htm

28. Zitto ME, Piotrkowski R, Gallego A, Sagasta F, Benavent-Climent A (2015) Damage assessed by wavelet scale bands and $b$ value in dynamical tests of a reinforced concrete slab monitored with acoustic emission. Mech Syst Signal Process 60-61:75-89. https ://doi.org/10.1016/j.ymssp.2015.02.006

29. Schumacher T, Higgins CC, Lovejoy SC (2011) Estimating operating load conditions on reinforced concrete highway bridges with $b$ value analysis from acoustic emission monitoring. Struct Health Monit Int J 10:17-32. https://doi.org/10.1177/147592171036542 4

30. Butt SD, Limaye V, Mufti AA, Bakht B (2004) Acoustic transmission technique for evaluating fatigue damage in concrete bridge deck slabs. Struct J 101:3-10. https://doi.org/10.14359/12992

31. Yuyama S, Li Z-W, Yoshizawa M, Tomokiyo T, Uomoto T (2001) Evaluation of fatigue damage in reinforced concrete slab by acoustic emission. NDT E Int 34:381-387. https://doi. org/10.1016/S0963-8695(01)00004-4

32. Ohtsu M (2015) Acoustic emission and related non-destructive evaluation techniques in the fracture mechanics of concrete: fundamentals and applications. Woodhead Publishing, Cambridge

33. Tomoki S, Hiroyasu O, Shohei M, Kian CH, Hiroshi O, Toshiro $\mathrm{K}$ (2012) Damage evaluation for concrete bridge deck by means of stress wave techniques. J Bridge Eng 17:847-856. https://doi. org/10.1061/(ASCE)BE.1943-5592.0000373

34. Anay R, Cortez TM, Jáuregui DV, ElBatanouny MK, Ziehl P (2016) On-Site acoustic-emission monitoring for assessment of a prestressed concrete double-tee-beam bridge without plans. J Perform Constr Facil 30:04015062. https://doi.org/10.1061/(ASCE) CF.1943-5509.0000810

35. Nair A, Cai CS (2010) Acoustic emission monitoring of bridges: review and case studies. Eng Struct 32:1704-1714. https://doi. org/10.1016/j.engstruct.2010.02.020

36. Golaski L, Gebski P, Ono K (2002) Diagnostics of reinforced concrete bridges by acoustic emission. J Acoust Emiss 20:83-89

37. Shiotani T, Nishida T, Asaue H, Kobayashi Y (2016) Interpretation of fatigue damage evolution in RC slabs by means of innovative 3D AE tomography. In: Saouma, Bolander J, Landis E (eds) 9th International Conference on Fracture Mechanics of Concrete and Concrete Structures. FraMCoS-9V. https://doi.org/10.21012 /FC9.225

38. Bayane I, Mankar A, Brühwiler E, Sørensen JD (2019) Quantification of traffic and temperature effects on the fatigue safety of a reinforced-concrete bridge deck based on monitoring data. Eng Struct 196:109357. https://doi.org/10.1016/j.engst ruct.2019.109357

39. EN N (2017) 1330-9. Non-destructive testing—-terminology—part 9: terms used in acoustic emission testing. https://www.boutique. afnor.org/standard/nf-en-1330-9/non-destructive-testing-termi nology-part-9-terms-used-in-acoustic-emission-testing/artic le/842412/fa060458

40. AFIAP (2009) Guide AFIAP emission acoustique 2009|signal électriquelContrôle non destructif. In: Scribd. https://fr.scrib d.com/document/246989415/Guide-AFIAP-Emission-Acoustique -2009. Accessed 22 Jan 2020

41. Mistras G INC (2015) Sensor highway III, user's manual. https:// www.physicalacoustics.com/by-product/sensor-highway-iii

42. Hardy JHR (2003) Acoustic emission/microseismic activity: volume 1: principles, techniques and geotechnical applications. CRC Press, Boca Raton

43. Whitehurst EA (1966) Evaluation of concrete properties from sonic tests. American Concrete Institute, Farmington Hills

44. Hillerborg A (1983) Analysis of one single crack. Elsevier, Amsterdam

45. Vasudevan AK, Sadananda K, Glinka G (2001) Critical parameters for fatigue damage. Int J Fatigue 23:39-53. https://doi. org/10.1016/S0142-1123(01)00171-2

46. Md Nor N, Ibrahim A, Muhamad Bunnori N, Mohd Saman H (2013) Acoustic emission signal for fatigue crack classification on reinforced concrete beam. Constr Build Mater 49:583-590. https://doi.org/10.1016/j.conbuildmat.2013.08.057

47. Aggelis DG (2011) Classification of cracking mode in concrete by acoustic emission parameters. Mech Res Commun 38:153-157. https://doi.org/10.1016/j.mechrescom.2011.03.007

48. Aggelis DG, Soulioti DV, Sapouridis N, Barkoula NM, Paipetis AS, Matikas TE (2011) Acoustic emission characterization of the fracture process in fibre reinforced concrete. Constr Build Mater 25:4126-4131. https://doi.org/10.1016/j.conbuildmat.2011.04.049

49. RILEM TC 212-ACD (2010) Recommendation of RILEM TC 212-ACD: acoustic emission and related NDE techniques for crack detection and damage evaluation in concrete*. https://link. 
springer.com/article/10.1617/s11527-010-9640-6. Accessed 6 Apr 2020

50. Ohno K, Ohtsu M (2010) Crack classification in concrete based on acoustic emission. Constr Build Mater 24:2339-2346. https:// doi.org/10.1016/j.conbuildmat.2010.05.004

51. Xu ZZ, Wang Y, Wu SX, Wang Y (2013) Damage evaluation of concrete based on acoustic emission $b$ value. Appl Mech Mater 395-396:515-519. https://doi.org/10.4028/www.scientific.net/ AMM.395-396.515

52. Gutenberg B (2013) Seismicity of the earth and associated phenomena. Read Books Ltd, Redditch

53. Sammonds PR, Meredith PG, Murrell SAF, Main IG (1994) Modelling the damage evolution in rock containing pore fluid by acoustic emission. In: Rock mechanics in petroleum engineering. Society of petroleum engineers. https://www.onepetro.org/confe rence-paper/SPE-28142-MS

54. Kaphle MR (2012) Analysis of acoustic emission data for accurate damage assessment for structural health monitoring applications. Queensland University of Technology, Brisbane
55. Bunnori NM, Lark RJ, Holford KM (2011) The use of acoustic emission for the early detection of cracking in concrete structures. Mag Concr Res 63:683-688. https://doi.org/10.1680/ macr.2011.63.9.683

56. Chatterji S (2003) Freezing of air-entrained cement-based materials and specific actions of air-entraining agents. Cem Concr Compos 25:759-765. https://doi.org/10.1016/S0958-9465(02)00099-9

57. Aggelis D, Shiotani T, Momoki S, Hirama A (2009) acoustic emission and ultrasound for damage characterization of concrete elements. ACI Mater J. https://doi.org/10.14359/51663333

Publisher's Note Springer Nature remains neutral with regard to jurisdictional claims in published maps and institutional affiliations. 